\title{
Research Paper \\ Network Analysis and Appraisal of Social Capital of Beneficiaries for Rural Sustainable Development (Case Study: Bazijan Village, Mahalat County, Markazi Province)
}

\author{
*Mehdi Ghorbani ${ }^{1}$, Gholamreza Hadarbadi², Fariba Ebrahimi Azarkharan ${ }^{3}$, Adele Khavar ${ }^{3}$
}

1. Assistant Professor, Department of Reclamation of Arid and Mountainous Regions, Faculty of Natural Resources, Agriculture \& Natural Resources Campus, University of Tehran, Karaj, Iran.

2. Assistant Professor, Extension \& Public Participation Bureau, Forests, Range and Watershed Management Organization, Tehran, Iran.

3. PhD Candidate, Department of Reclamation of Arid and Mountainous Regions, Faculty of Natural Resources, Agriculture \& Natural Resources Campus, University of Tehran, Karaj, Iran.

Citation: Ghorbani, M., Hadarbadi, Gh. R., \& Ebrahimi Azarkharan, F., Khavar, A. (2016). Network Analysis and Appraisal of Social Capital of Beneficiaries for Rural Sustainable Development (Case Study: Bazijan Village, Mahalat County, Markazi Province). Journal of Rural Research, $7(2), 406-421$

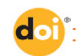

Received: 05 Mar. 2016 Accepted: 21 May 2016

Key words: Empowerment, Bonding social capital, Local community, Adaptive co-management

\begin{abstract}
A B S T R A C T
Social capital is a fundamental prerequisite for local sustainable development and social empowerment. The present study is an attempt to analyze the bonding of social capital of local beneficiaries in the Bazijan village of Mahalat County. Regarding the importance of adaptive co-management and reinforcement of social capital, the trust and participation ties of beneficiaries need to be explored. Accordingly, these aspects were investigated through network analysis questionnaire and direct interviews with all local beneficiaries (present as rural development micro-groups). It was found that the level of trust, participation, cohesion, and social capital elevated from a low state prior to project implementation to an optimum level post project implementation. The speed of trust and participation transfer among actors also increased following project implementation. This project also led to a higher unity among individuals such that social empowerment was realized desirably in this village. Thus, it can be asserted that the implementation of this project resulted in a higher bonding of social capital, which further results in less social seclusion, higher social welfare, and extensive collaboration of residents.
\end{abstract}

\section{Extended Abstract}

\section{Introduction}

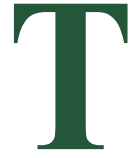

rust has a profound link with risk. It is a reliable solution for increasing resilience against various risks. Increased trust is what Emile Durkheim called "moral density," and contemporary writers discuss it under the heading of "social capital". The notion of trust has increasingly drawn wide attention of various disci- plines. Trust is argued to contribute positively to emerging cooperative behavior, "adaptive organizational forms", conflict reduction, decreased transaction costs, and the ability to organize. Every social relationship or social system benefits from trus j̈t since it lessens disorder and facilitates goal achievement. Communication facilitates trust and reduces symptoms related to mass ignorance that prevents spontaneous collective action. Bridging social capital is one of the most important components of the social capital for sustainable local and regional development.

\section{* Corresponding Author:}

Mehdi Ghorbani, PhD

Address: Department of Reclamation of Arid and Mountainous Regions, Faculty of Natural Resources, Agriculture \& Natural Resources Campus, University of Tehran, Daneshkadeh Ave., Karaj, Iran.

Tel: +98 (26) 32249314

E-mail: mehghorbani@ut.ac.ir 
Given the importance of social capital in capacity building, strengthening the mobilization of the local communities, and for local sustainable development, this study focused on the relationship between trust and cooperation, which are important aspects of social capital. The four villages of Dust Abad, Bostaq, Zangooii and Se-Qaleh city in the Iranian province of South Khorasan were included in the study. The social capital of local stakeholder networks for sustainable development in the four areas targeted by the RFLDL project was investigated.

\section{Methodology}

Conducting a survey, using direct observation, and interviews with target groups helped in identifying the first nodes of the network consisting of the head of small development committees (funds) (such as decision-makers in each sub-group) in each area. Based on the complete network method, a network analysis questionnaire was developed, and questions about trust and partnership between residents were asked. During the full network method development, all heads of small development committees including 63 people in four districts were studied. It should be noted that the indicators examined in this article are related to the large-scale network of relations between the heads of the four regions. Network macro-level indicators, such as density, reciprocity, transitivity, geodesic distance and the average distance of intra-group and between group relations, were calculated using the UCINET Software.

\section{Results}

Creation of an integrated network is the appropriate way to achieve sustainable development. One of the goals of the International RFLDL Project was strengthening communication and interaction of subgroupheads, as community leaders in the four regions, in order to strengthen social capital through social-system resilience, in the face of dangers and environmental stresses, like desertification and climate change, expanding upon them. In this paper, the relationship of trust and partnership as the most important dimensions of social capital for heads of the committees is examined. This reviews and assesses the effectiveness of the RFLDL project from a social viewpoint. The results indicate that, prior to the implementation of the RFDL project, indexes such as trust, cooperation, solidarity and social capital were weak. However, after the implementation of the RFLDL project, these indexes increased and reached moderate levels. Also the indexes measuring the average geodesic distance, the speed of trust, and cooperation exchange between the people increased after the program com- pared to their levels before the project implementation, suggesting a greater unity in the study area.

The EI-index diagnosed an increasing amount of intragroup bridges, which doubled after the implementation of the projects in the four regions. In other words, RFLDL's measures supported the formation of more sustainable and coherent networks among the leaders, and mutual trust and mutual cooperation increased. The results showed that social capital and social empowerment increased to double levels, which will also support the reduction of social exclusion.

After the implementation of the project, the outer group social capital among the four regions has increased, which in turn asserts reduced social ignorance, increases social welfare, and improves the participation of residents. Based on the survey methodology and results, it can be concluded that network analysis can measure and evaluate useful indicators in relation to social factors affecting local sustainable development and empowerment.

\section{Discussion}

The formation and strengthening of community organizations achieved increased social welfare and wider participation in decision-making. To achieve successful social empowerment and local sustainable development and to fight social ignorance, social capital and social cohesion, with an emphasis on trust and cooperation, need to be further built. Certainly, with the accumulation of social capital, the quality of life in the project area will also increase. Stronger trusting ties between the committees in the four regions support the sustainable rural development and will be an important step in strengthening the spirit of cooperation between them, which is the opposite of social exclusion and an important contribution to socio-ecological resilience. 


\title{
ارزيابى سرمايه اجتماعى شبكه ذيىنفعان محلى درواستاى توانمندسازى جوامع روستايى (مورد

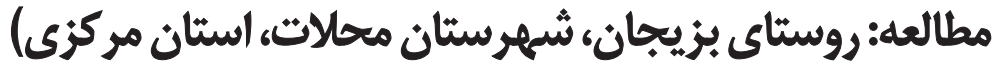

\author{
•مهدى قربانى'، غلامرضا هادربادى'، فريبا ابراهيمى آذرخران"، عادله خاور” \\ 1- استاديار، كروها احياى مناطق خشك و كوهستانى، يرديس كشاورزى و منابع طبيعى، دائشكده منابع طبيعى، دائشكاه تهران، كرج، ايران.

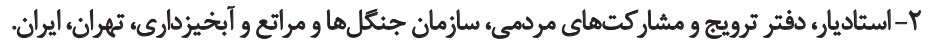

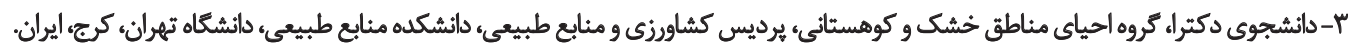

\begin{abstract}
حكبد

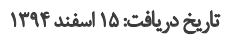

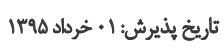

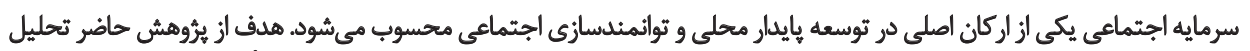

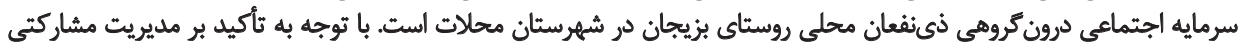

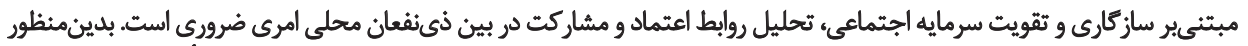

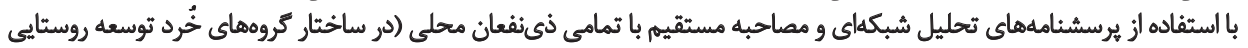

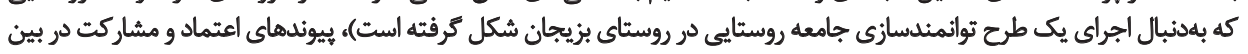

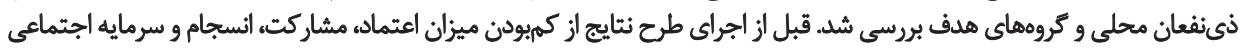

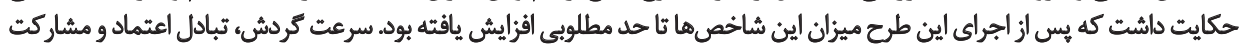

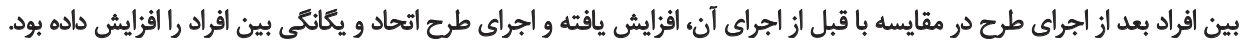

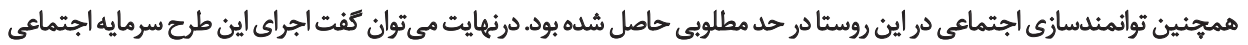

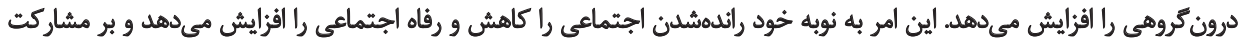
كسترده ساكئان روستا اثر مي كذارد.

كليدوأوهها:

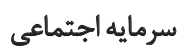

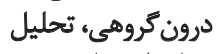

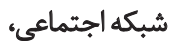
توانمندسازى جامعه محلى، مديريت ماريتي مشاركتى مبتنىير

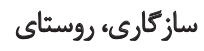
بزيجان
\end{abstract}

عموماً در دستيابى به توانمندسازى جوامع محلى درراستاى تحقق بإيق

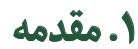

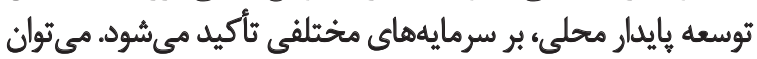

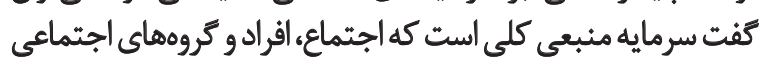

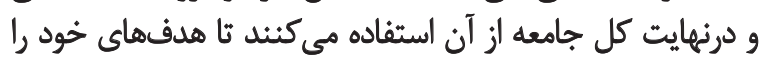

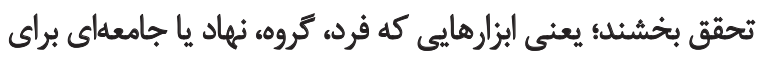

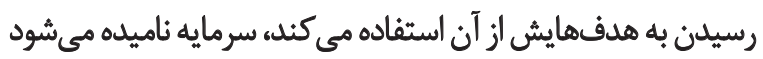

.(Mousavi, 2006; Farahani, Ainali, \& Abdoli, 2013)

امروزه در كنار سرمايههاى اقتصادى و فرهنئى و نمادين،

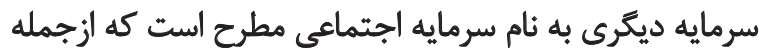

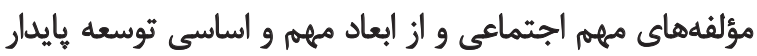

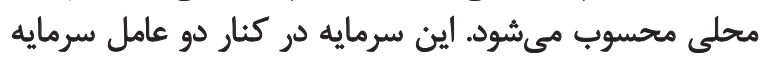

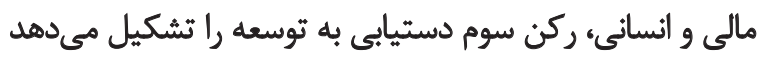

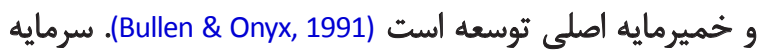

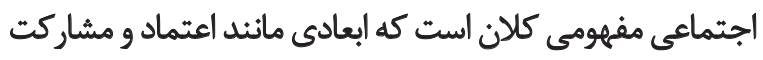

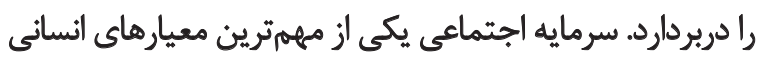

توسعه در مفهوم كلى خود بلمعناي ارتقاى سطح مادى و

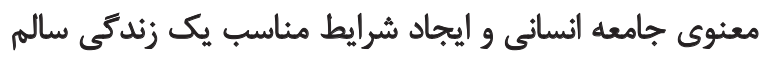

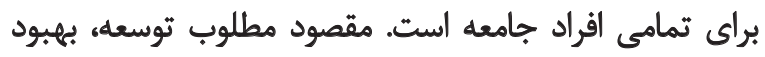

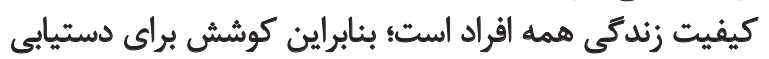

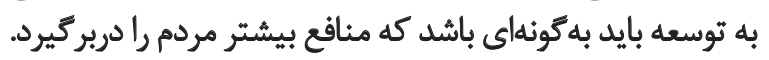

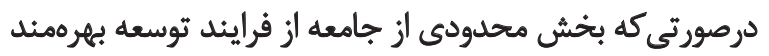

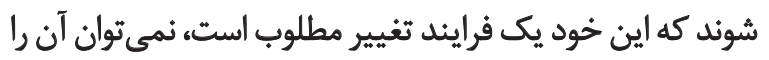
توسعه ناميد (Salari Sardari, Beiranvandzadeh, Alizadeh, 2012).

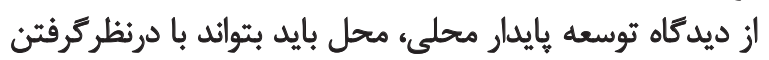

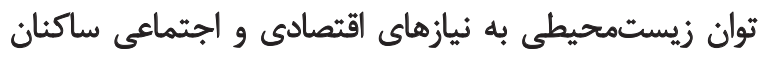

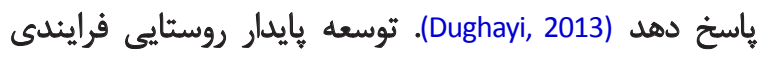

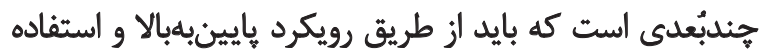

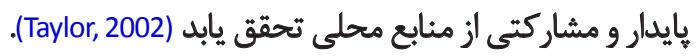


اجتماعى است. پاتثنام سرمايه اجتماعى را بلهورت شبكههايى از

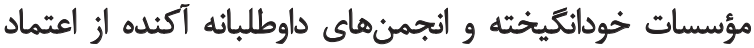

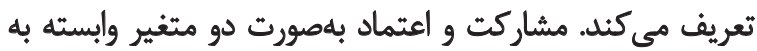

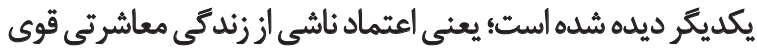

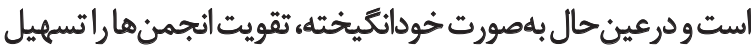

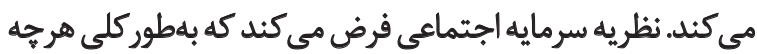

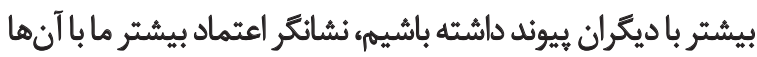
و برعكس خواهد بود (Putnam, 2000; Ghafari, 2011).

اعتماد بيوند عميقى با مخاطرات دارد. اعتماد راهحلى براى

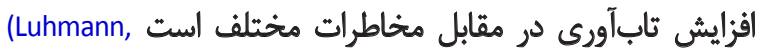

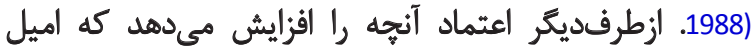

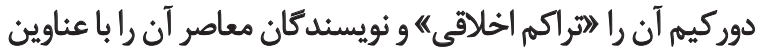

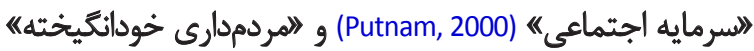
(Fukuyama, 2001)

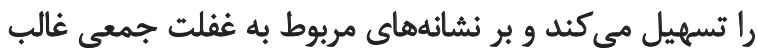

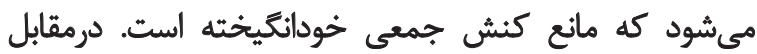

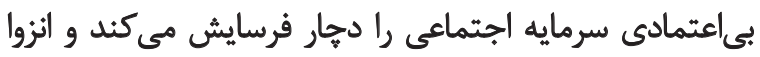

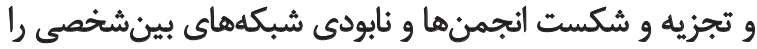

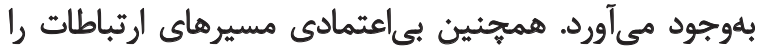

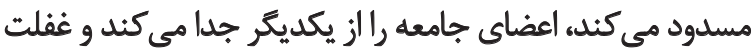

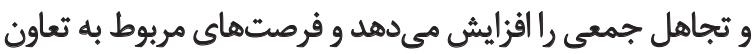
و همكارى را مسدود مى كند (Ghafari, 2005).

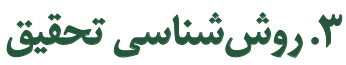
معرفى منطقه مطالعهشده

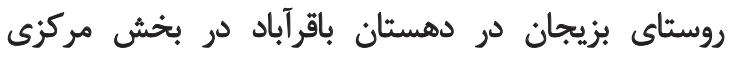

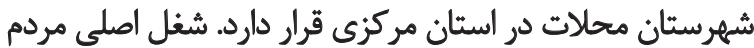

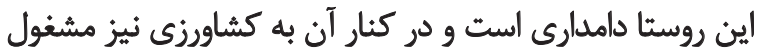

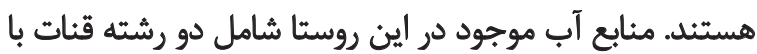

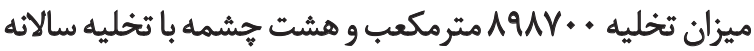

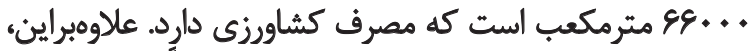

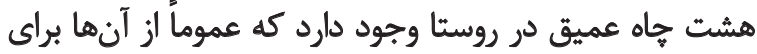

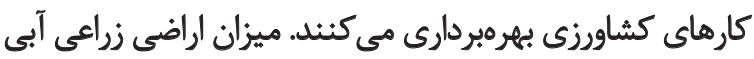

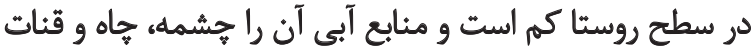

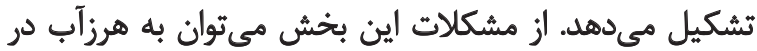

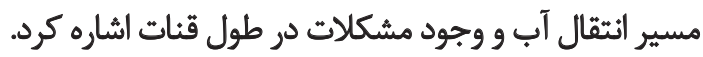

معرفي طرح التوى ايرانى مشاركت و ثوانمثدسازى جوامع محلى با وويكرد شبكه هاي اجتماعى (S.N.C.E.I.P)

اين طرح در روستاى بزيجان با هدف مديريت يكيارجه و وايدار

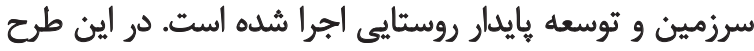
براى اولينبار ساختار جديد سياست تذاري باري با عنوان الكميته
مرتبط با ميزان تابآورى در يك سيستم اجتماعى است.

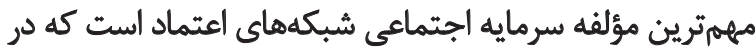

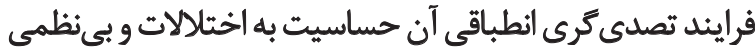

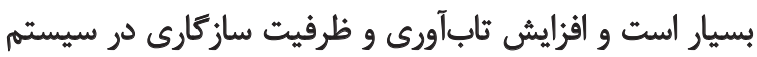
اجتماعى به ميزان اعتماد در شبكه وابسته است (Stien, 2011).

سرمايه اجتماعى از ويزّكى خودزايى يا خودمولدى برخوردار

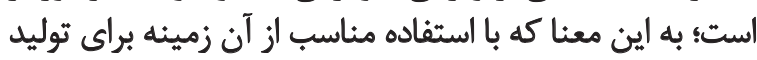

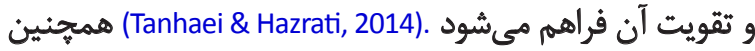
سرمايه اجتماعى موجب فراكيرى اعتماد متقابل مردم به يكديخر

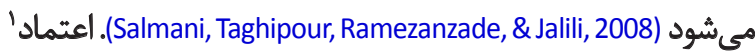

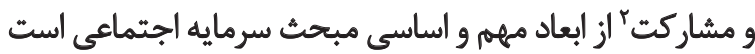
Pretty \& Ward, 2001)

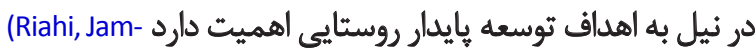
(shidi, Jamini, Cheraghi, 2013

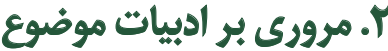

سرمايه اجتماعى درون گروهى به بيوندهايى اجتماعى اشاره

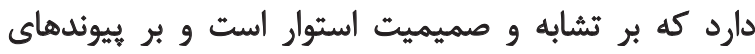

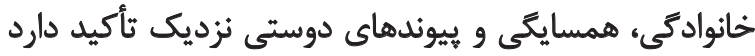

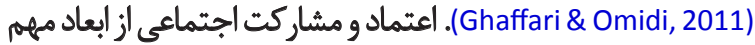

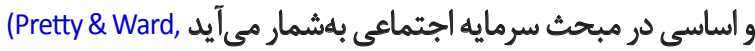

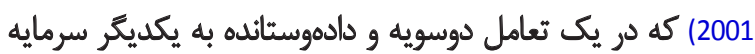
اجتماعى را شكل مي دهند (Ghorbani et al., 2013).

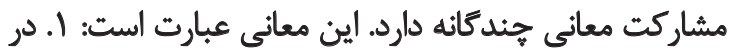

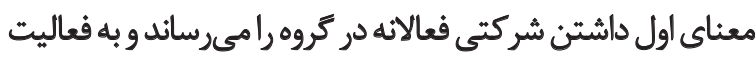

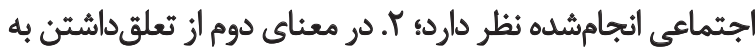

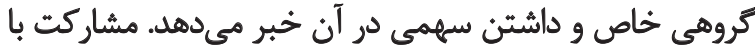

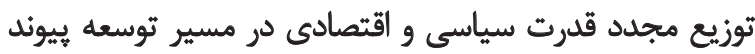

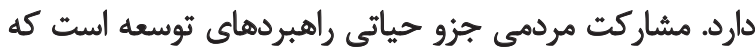

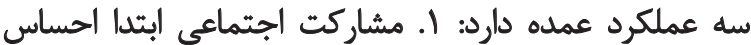

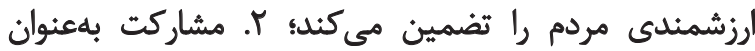

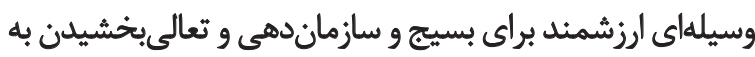

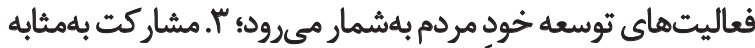

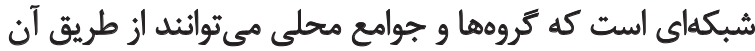

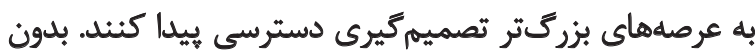

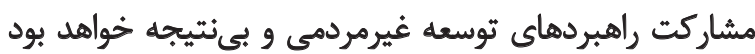
.(Shafiei, Abdolhoseini, Yari, Kargar, \& Pouyafar, 2013)

تُعد ديكر سرمايه اجتماعى اعتماد است كه درحقيقت بيش ريشرط

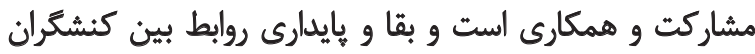
به اعثماد افراد به يكديكر وابسته است. اعتماد مؤلفه مهم سرمايه بـايه

1. Trust

2. Collaboration 
در بين ذى نفعان محلى در مراحل مختلف قبل از اجراى طرح،

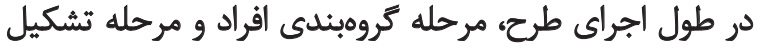

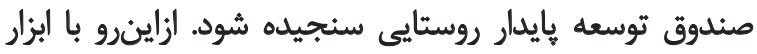

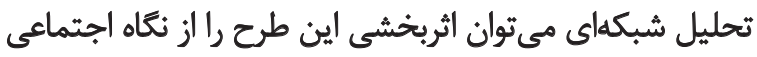
تخليل كرد.

در اين تحقيق ابتدا براساس روش ييمايشى و از طريق مشاهده

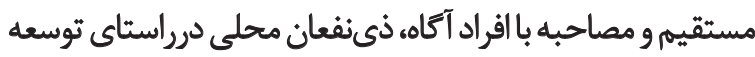

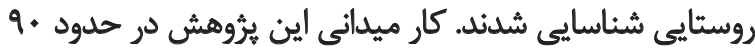

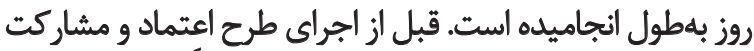

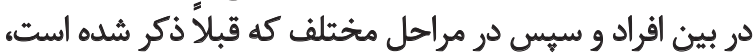

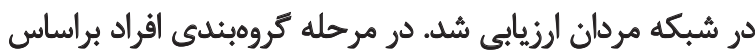

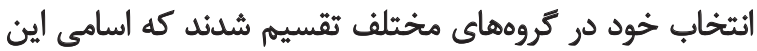
كروهها در جدول شماره ه نشان داده شده است.

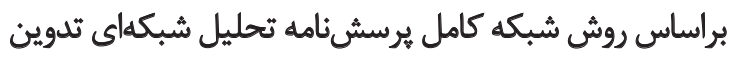

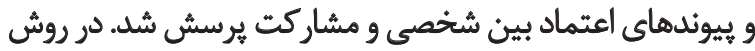

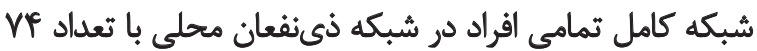

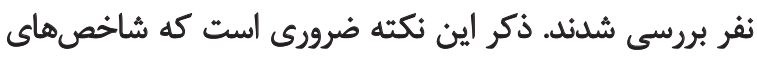

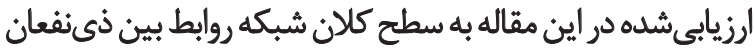

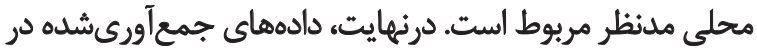

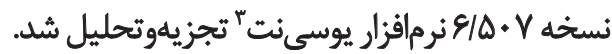

$$
\text { شاخصهاي تحليل شبكهاي }
$$

شاخصهاى مدنظر در اين تحقيق در سطح كلان شبكه سنجيده

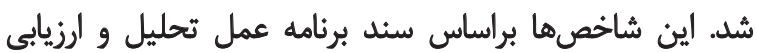

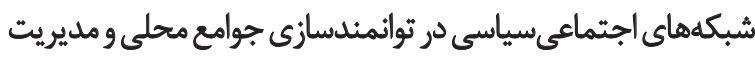
جامع سرزمين انتخاب شده است (Ghorbani, 2015b). درادامهامه هر

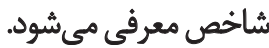

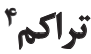

تراكم بلهورت نسبت تعداد كل بييوندهاى ارثباطى موجود در

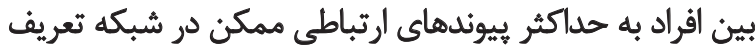

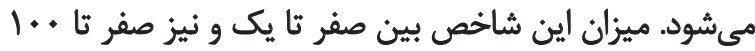

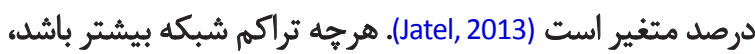

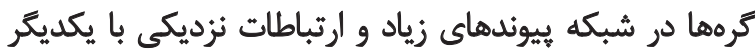

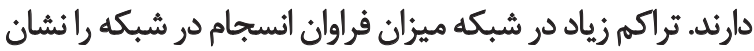

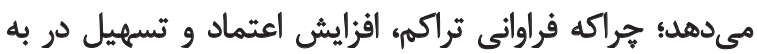

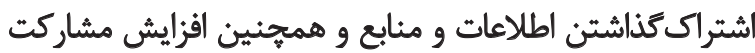

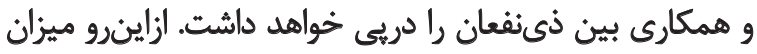

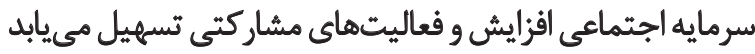

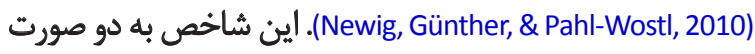

\section{UCINET}

4. Density
مديريت يكيارجها سرزمين) (L.I.M.C) در سطح شهرستان محلات

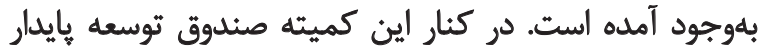

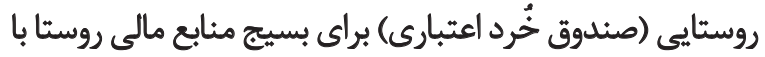

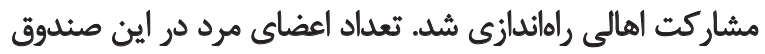

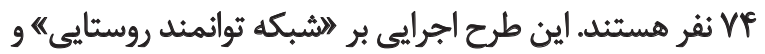

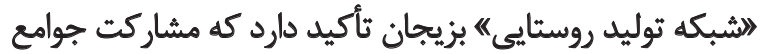

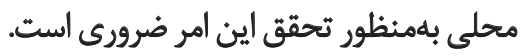

براى توانمندسازى اجتماعى و تقويت سرمايه اجتماعى، تحليل

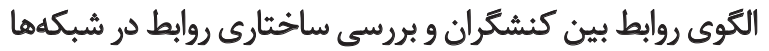

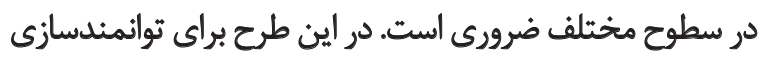

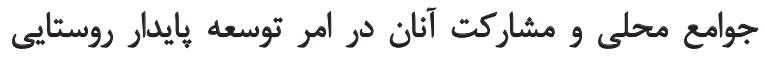

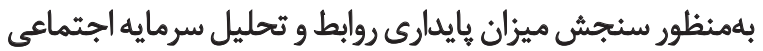
درون گروهى از رويكرد تحليل شبكه هاي اجتماعي (SNA) استفاده شده است (Ghorbani, 2015a).

$$
\text { روش تحليل شبكه الجتماعى }
$$

روش تحليل شبكداى ابزارى كتّى و رياضى است كه مى توان

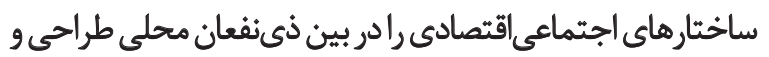

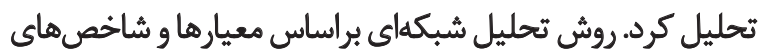

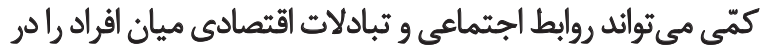

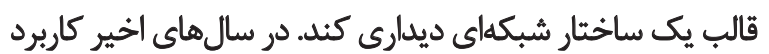

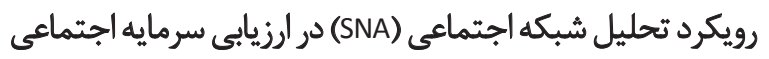
رونق يافته است. هدف تحليل شبكه اجتماعى مطالعه ساعي ساخت

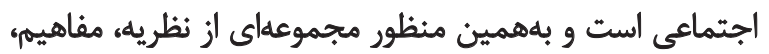

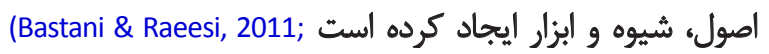
.Ebrahimi, Ghorbani, Salajegheh, \& Mohseni Saravi, 2014 تحليل شبكههاى اجتماعى با شناسايى ساختارهاى اجتماعى

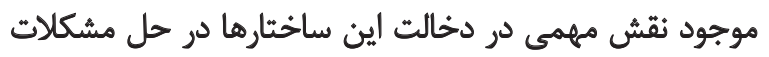

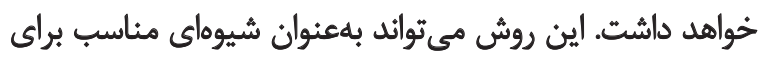

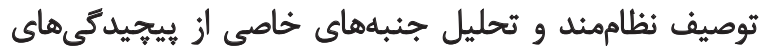

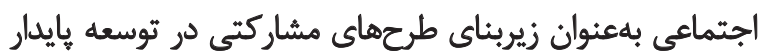
بهكاررود (Stein, Ernstson, \& Barron, 2011).

$$
\text { و وشמ كار }
$$

در اين تحقيق ذيىنفعان محلى يا گروههاى هدف مردان

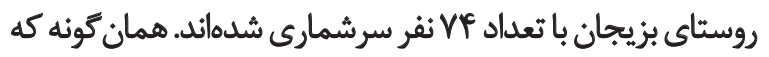

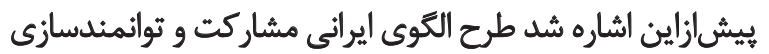

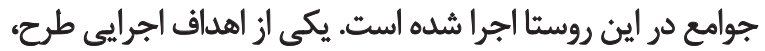

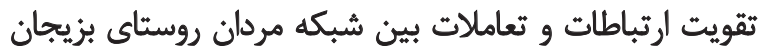

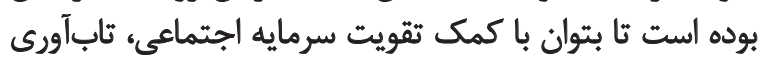

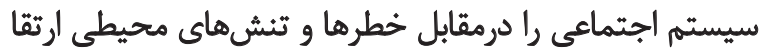

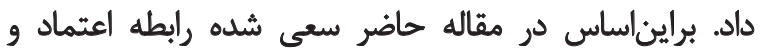

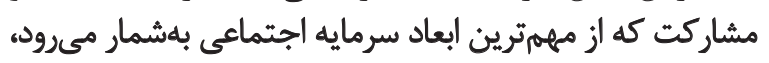




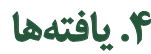

تحليل ساختارى ييوثدهاي اعتماد و مشاركت اجتماعى در سطح

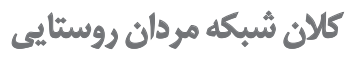

شاخصهاي تراكم، تمركز، اندازه و ميزان انسجام و سرمايه اجتماعى در شبكه مردان تركي

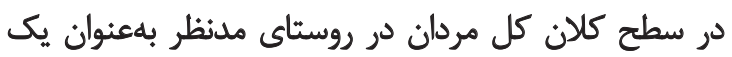

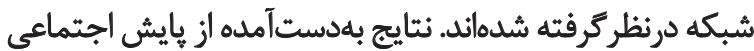

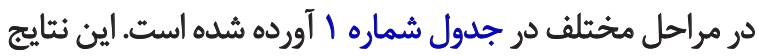

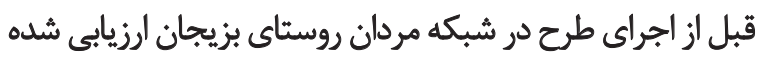

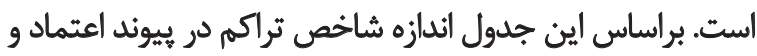

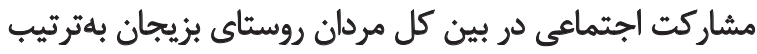

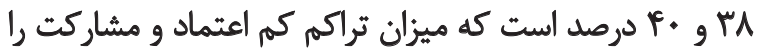

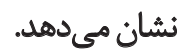

مرحله دوم يايش اجتماعى در سه روز انجام شد كه نتايج آن

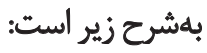

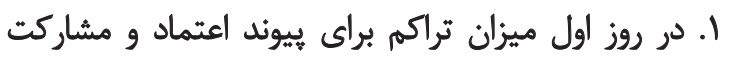

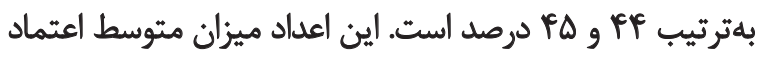

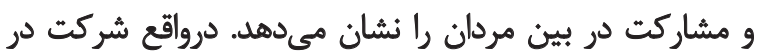

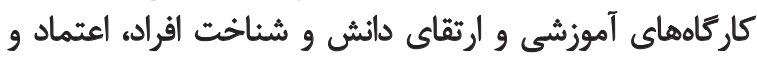
مشاركت را در بين آنان افزايش داده است

ז. در روز دوم ميزان شاخص تراكم براى بيوندهاي اعتماد و

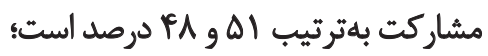

ب. شاخص تراكم در روز سوم براى بي بيوندهاى اعتماد و مشاركت بهترتيب عهم و اه درصد ارزيابى شده است.

براى انجام مرحله بعدى بايش اجتماعى (مرحله گروهبندى)

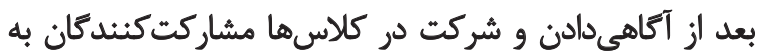

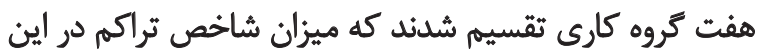

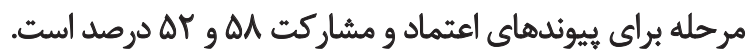

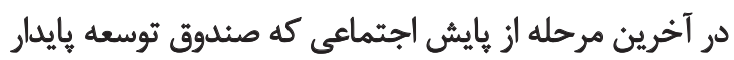

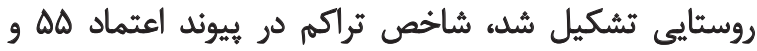

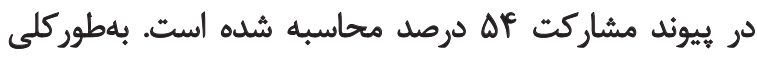

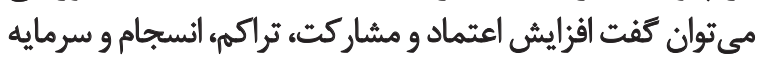

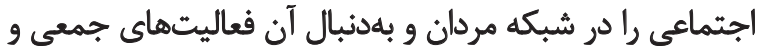

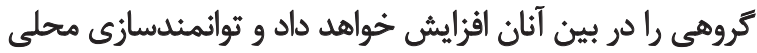

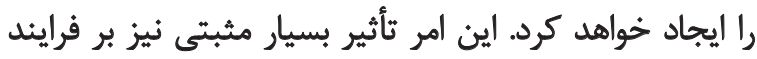

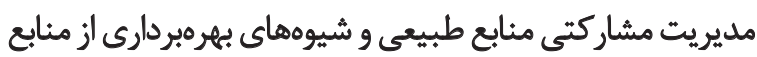

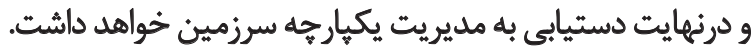

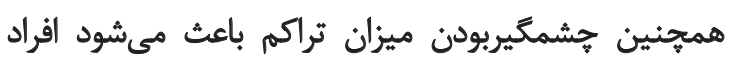

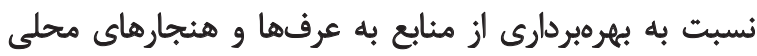

محاسبه هيشود: تراكم كل شبكه و تراكم درون كروهي كه

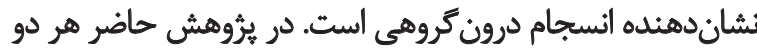
اين دو شاخصها محاسبه شده است.

\section{دوسويكى يبيوندهاه}

شاخص دوسويتى يكى از شاخصهاى مهارم در تعيين ميزان

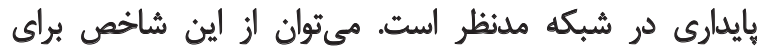

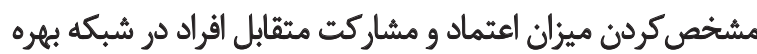

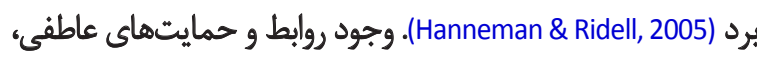

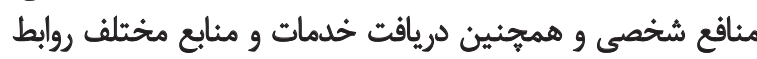

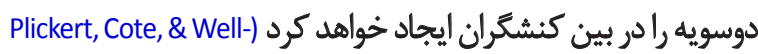

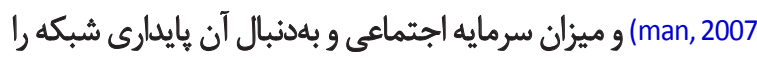
افزرايش خواهد داد (Suzuki, et al., 2010).

انتقال يافتكى ييوندهاء

اين شاخص از به اشتراك كذاشتن ييوندها بين سه فرد حاصل

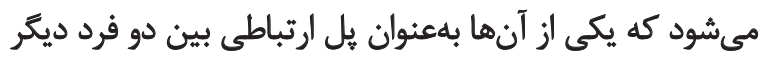

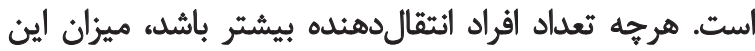

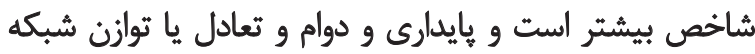

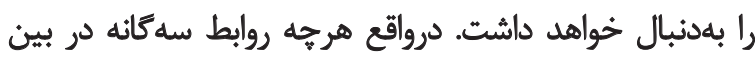

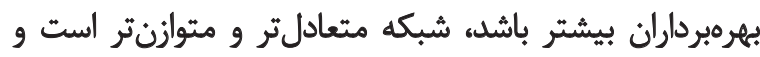

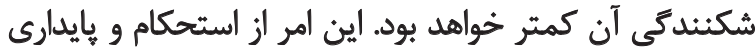
بيشتر روابط در شبكه حكايت دارد (Hanneman \& Ridell, 2005).

\section{ميانكين فاصله رئودزيك (كوتاهترين فاصله ميان دوكنشكر) "}

كوتاهترين فاصله ميان دو كنشكر عبارت است از فاصله

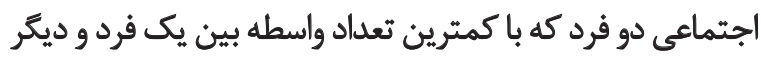

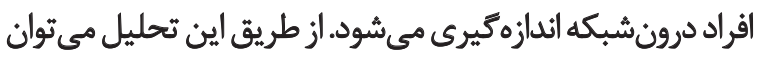

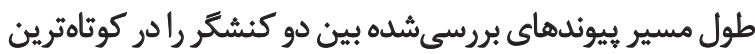

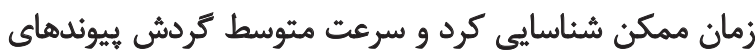

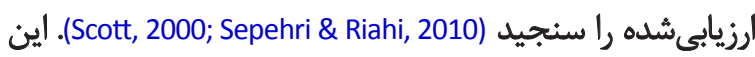

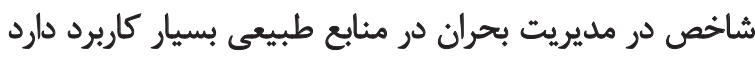

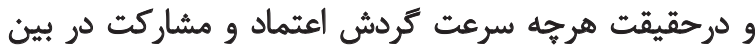

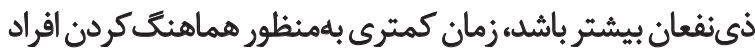

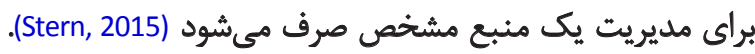

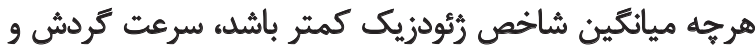

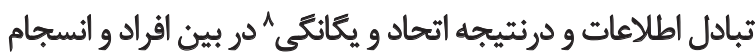
و سرمايه اجتماعى افزايش مىيابد (Salari, 2014).

5. Reciprocity

6. Transitivity

7. Average geodesic distance

8. Solidarity 


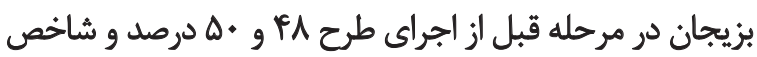

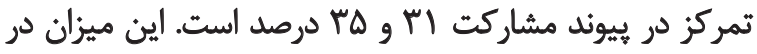

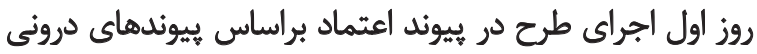

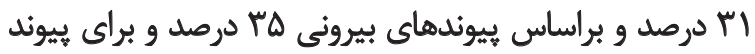

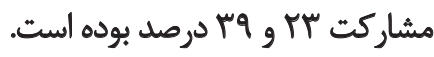

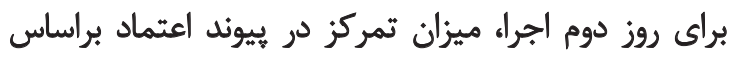

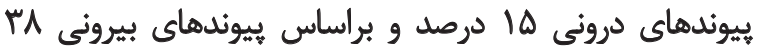

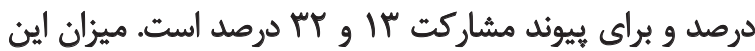

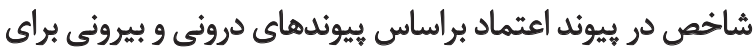

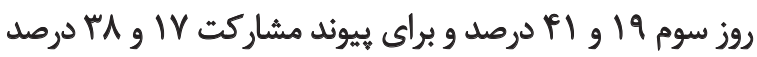

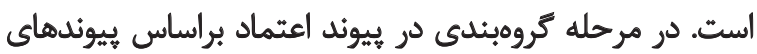

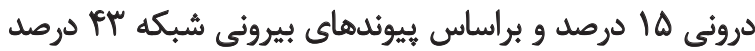

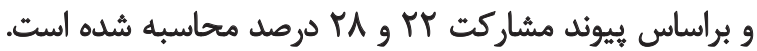

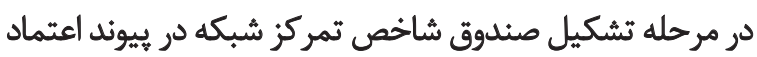

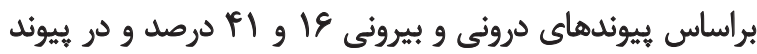

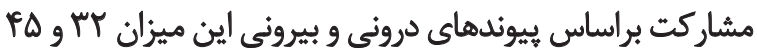

$$
\text { درصد است. }
$$

نتايج ميزان تمركز در شبكه مردان روستاى بزيجان در مراحل

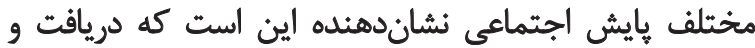

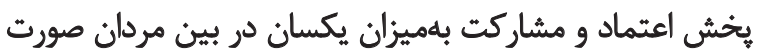

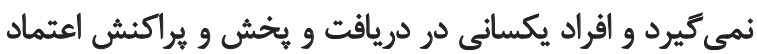

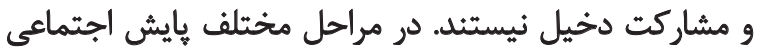

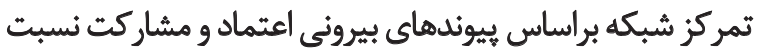

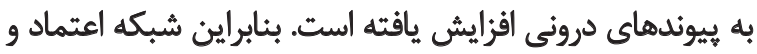
مشاركت براساس بيوندهاى بيرونى ساختار نيمهستار بارئى دارد و
بايبند باشند و احساس مسئوليت بيشترى داشته باشند. با توجه

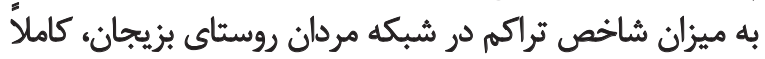

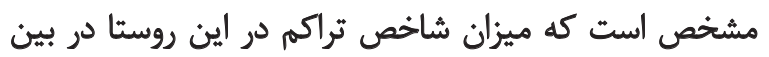

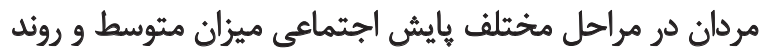

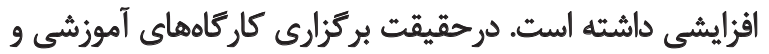

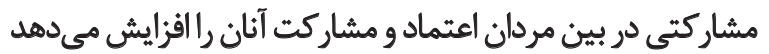

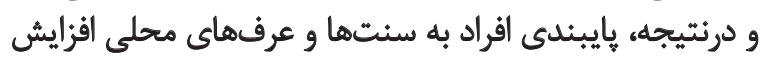

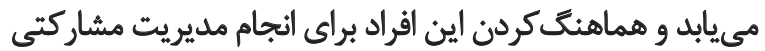

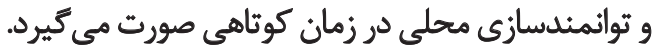

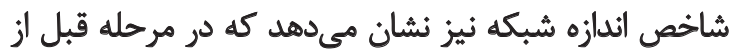

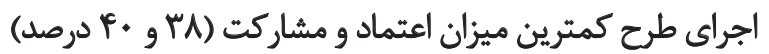

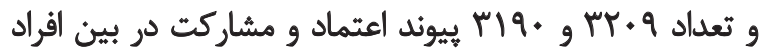

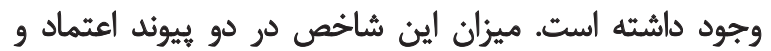

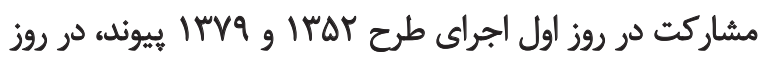

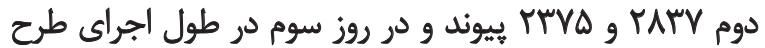

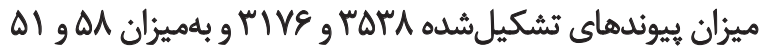

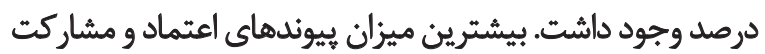

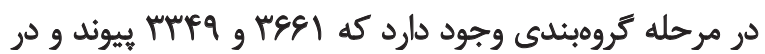

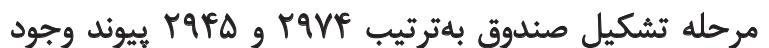

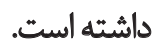

شاخص تمركز، شاخص ديكرى است كه در سطح كلان شبكه

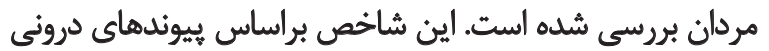

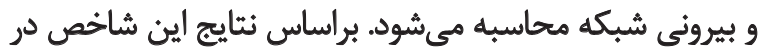

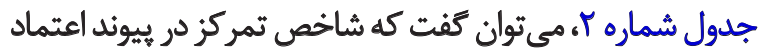

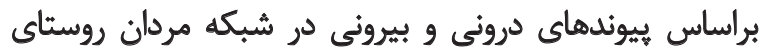

جدول ا. ميزان شاخصهاي تراكم و اندازه در شبكه مردان روستاى بزيجان.

\begin{tabular}{|c|c|c|c|c|}
\hline اندازه شبكه & تراكم (\%) & نوع ييوند & & مراحل با \\
\hline$\pi+9$ & ץی & اعتماد & & \multirow{2}{*}{ قبل از اجراى طرح } \\
\hline MIq. & f. & هشاركت & & \\
\hline Irat & pe & اعتماد & \multirow{2}{*}{ 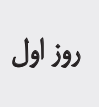 } & \multirow{6}{*}{ در طول اجراى طح } \\
\hline itra & PQ & مشاركت & & \\
\hline rerV & ه) & اعتماد & \multirow{2}{*}{ روز دوم } & \\
\hline TrVA & FA & مشاركت & & \\
\hline גנו ג & $\Delta \Lambda$ & اعتماد & \multirow{2}{*}{ روز سوم } & \\
\hline rive & D) & مشاركت & & \\
\hline PQSו & $\Delta S$ & اعتماد & & \multirow{2}{*}{ كروبيثدى } \\
\hline meq & ar & مشاركت & & \\
\hline rane & $\Delta \Delta$ & اعتماد & & \multirow{2}{*}{ تُكيل صندوق خُرد توسعه } \\
\hline TYYS & $\Delta \varphi$ & مشاركت & & \\
\hline
\end{tabular}


جدول r. تمركز شبكه براساس يهيوندهاى درونى و برونى اعتماد و مشاركت در سطح كل شبكه مردان.

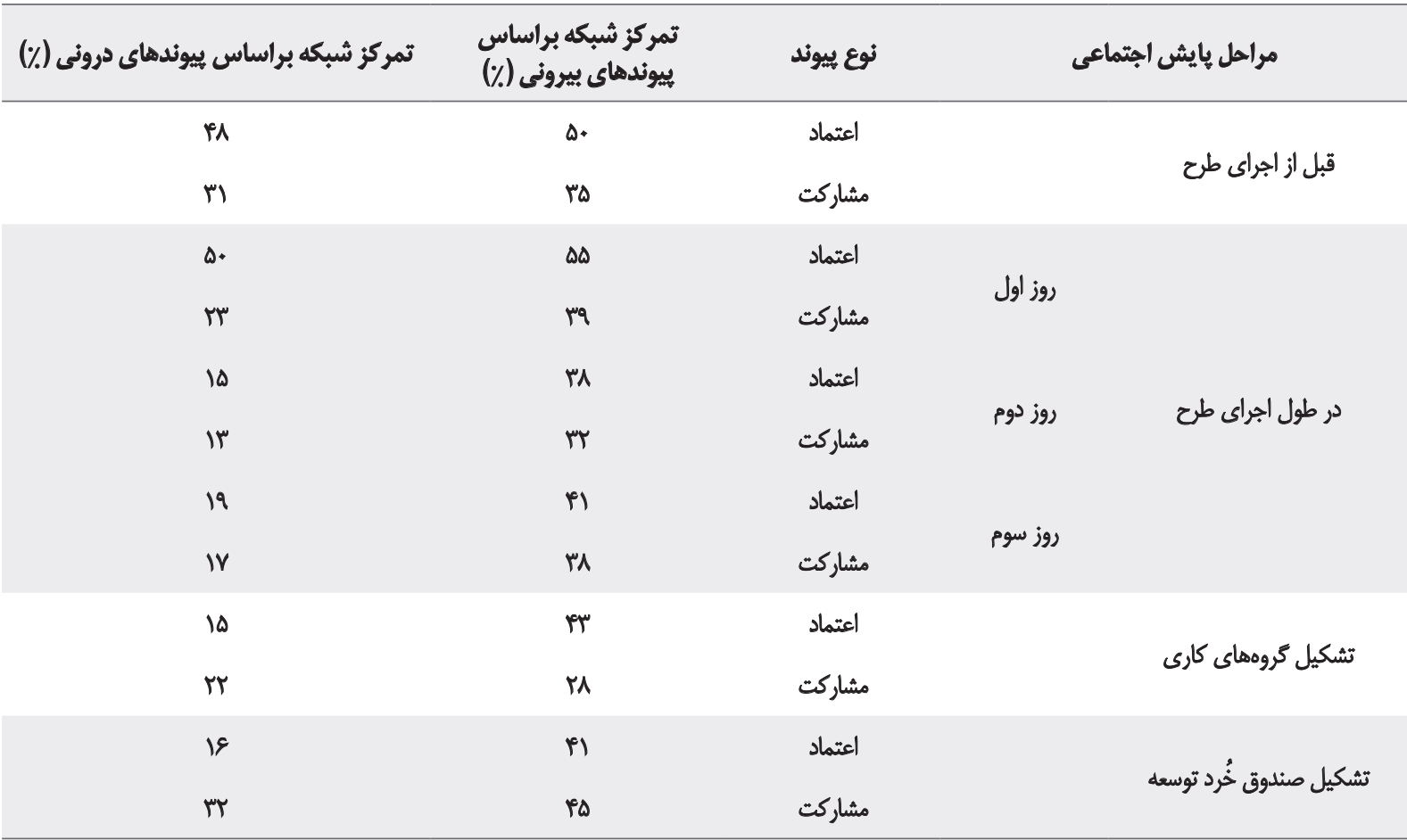

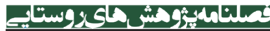

توانمئدسازى محلمي، نياز به افزايش و ثقويت اعتماد و مشاركت در

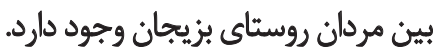

\section{ميزان دوسويكى ييوندهادر شبكه مردان روستاى بزيجان}

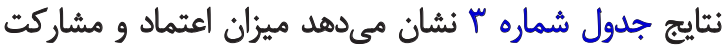

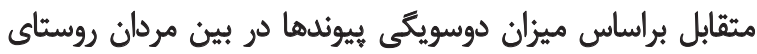

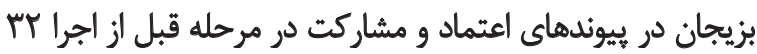

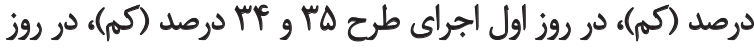

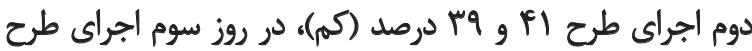

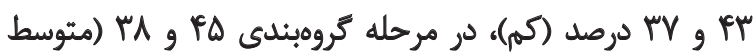

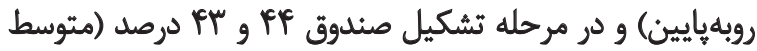

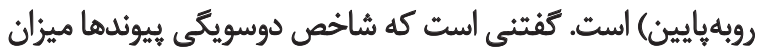

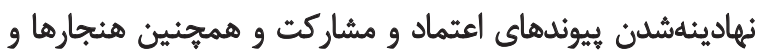

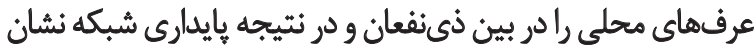

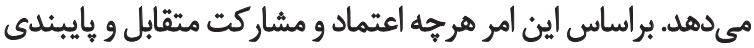

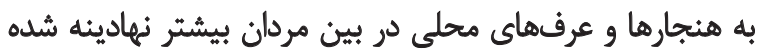

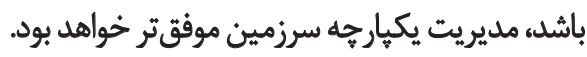

جشمكيربودن العتماد و مشاركت متقابل در بين افراد، ميزان

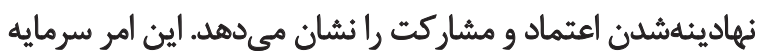

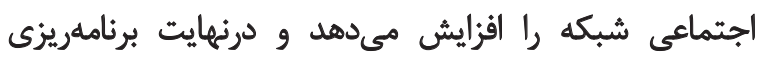

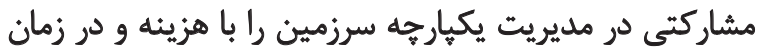

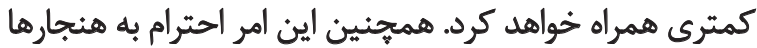

به كنشعَان مركزى وابسته است و كنشعران مركزى محدودى اعتماد و مشاركت را بخش مئش مي كنيند.

درباره بيوندهاى درونى در هر دو بيوند اعتماد و مشاركته

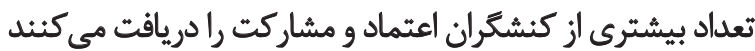

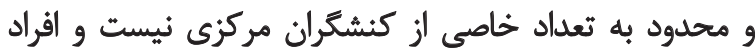

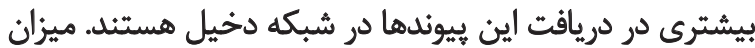

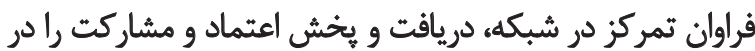

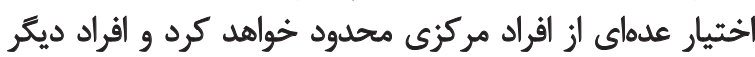

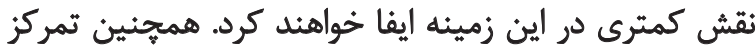

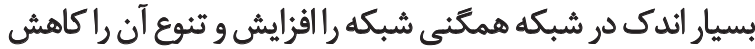

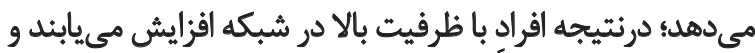

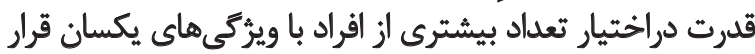

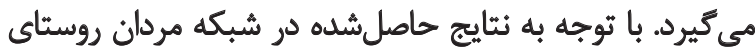

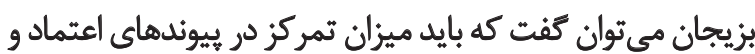

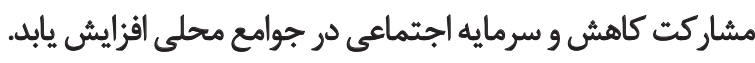
براساس سه شاخص تراكم، تمركز و اندازه شبكه، مى ثوان انسجام را در شبكه مردان روستاى بزيجان تجزيلوتحليل كرد. بنابر نتايج

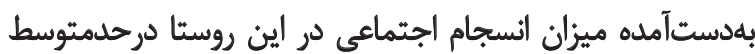

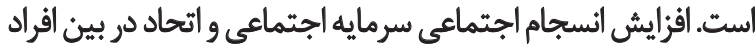

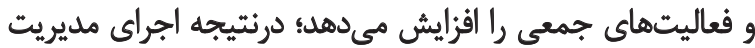

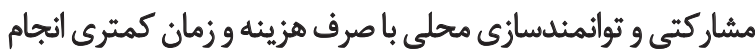
مي مود. برايناساس بهسبب افزايش انسجام و سرمايه اجتماعي و 
جدول ب.اندازه شاخص دوسويكى بييوندها و ايتقال يافتتى در سطح كل شبكه مردان روستاى بزيجان.

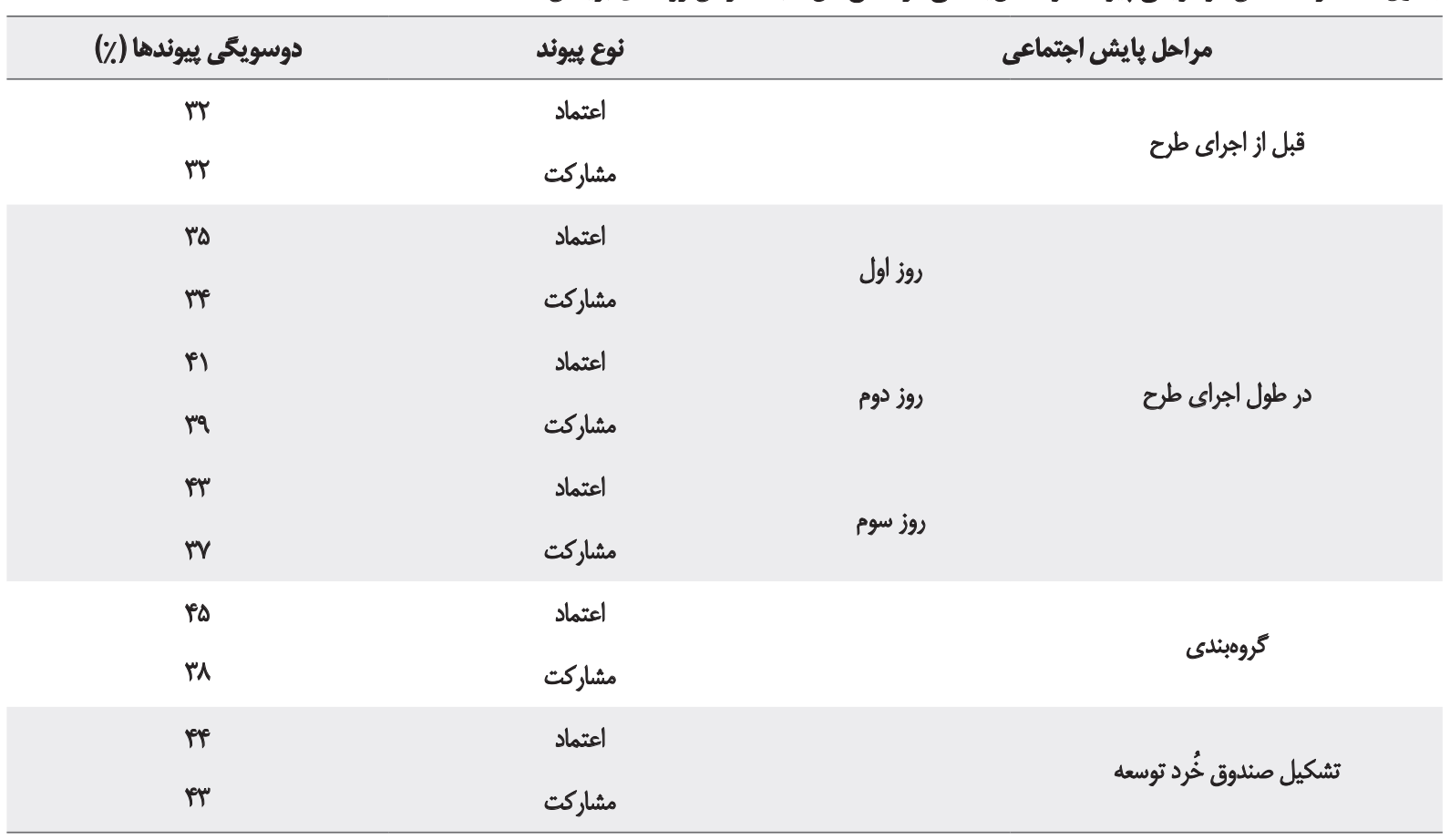

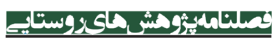

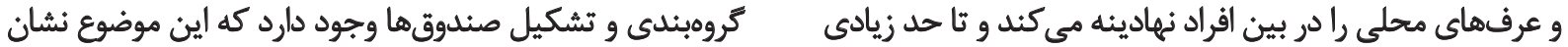

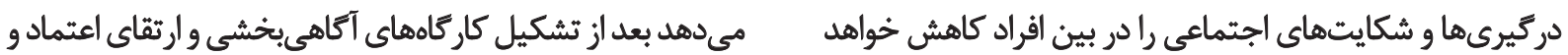

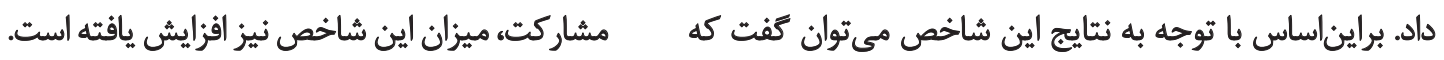

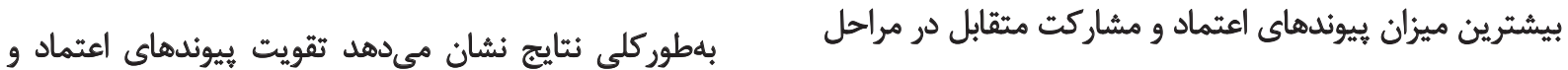
جدول P. شاخص ميانكين فاصله رثونزيك در بيوند اعتماد و مشاركت در شبكه مردان روستئي بزيجان.

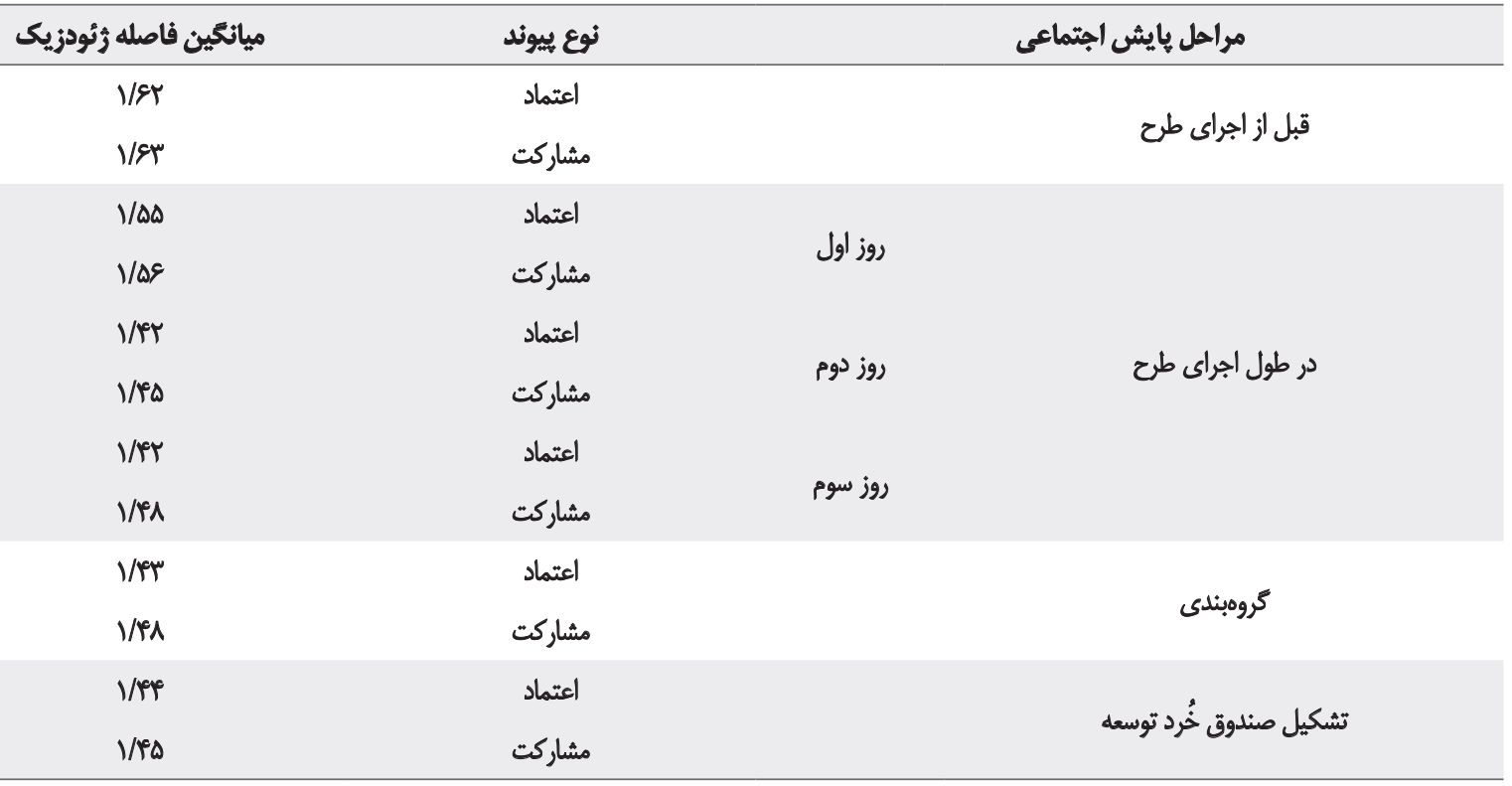


مختلف اجراى طرح در شبكه مردان روستاى بزيجان بررسى و نتايج آن در جدول شماره F آ آورده شده است مردان در مرحله قبل از اجراي طرح ميانكين كوتاثترين فاصله بين دو

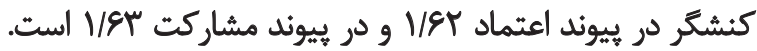

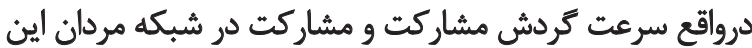

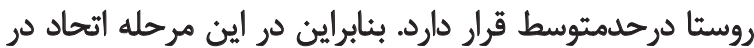

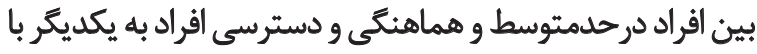
صرف زمان امكانيذير است.

ميانكين فاصله رئودزيك در بيوند اعتماد و مشاركت در شبكه

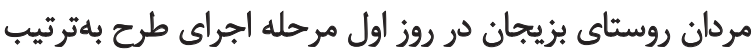

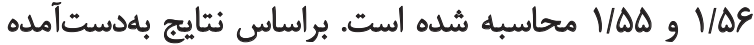

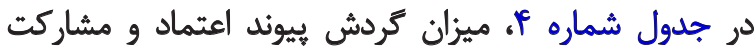

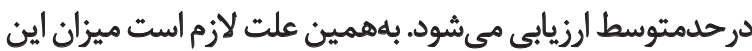

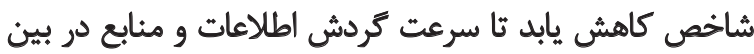

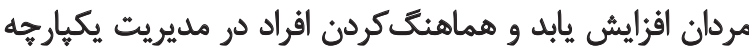

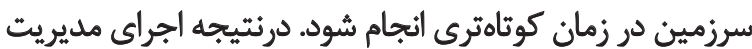

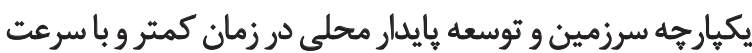
بيشترى تحقق يابد.

براساس جدول شماره f در طول اجراى طرح در روز دومي

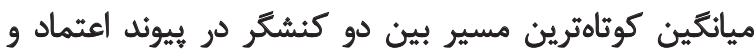

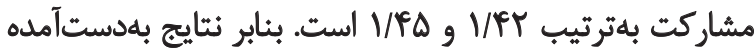

مشاركت متقابل در بين مردان اين روستا و نهادينهشدن اين

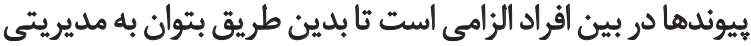

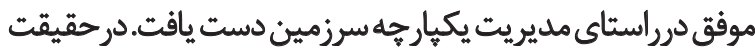

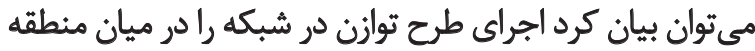

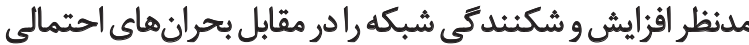

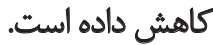

\section{ميانغين فاصله رئودزيك در ييوند اعتماد و مشاركت در} شبكه مردان روستاى بزيجان فئنان

اين شاخص بهعنوان ميانكين كوتاهترين فاصله بين يك جفت

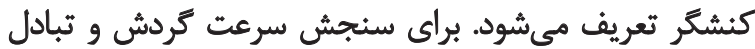

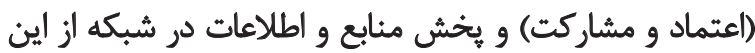

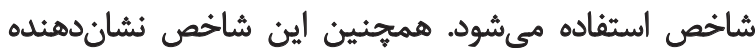

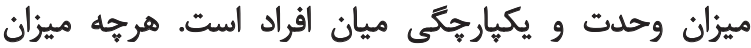

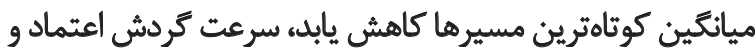

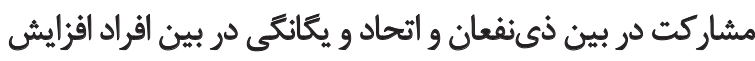

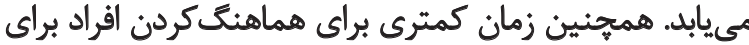

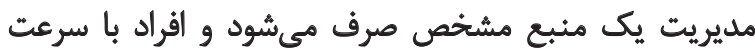

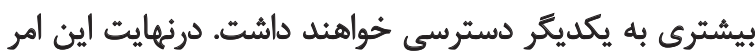

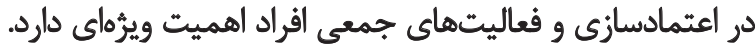

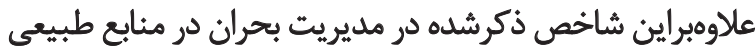
نيز بسيار كاربرد دارد. به همين سبب داين شائ شاخص در مران دراحل

جدول ه. ميزان تراكم در زيركروههاي شبكه مردان روستاى بزيجان.

\begin{tabular}{|c|c|c|c|}
\hline \multicolumn{2}{|c|}{ مرحله تشكيل صندوق } & \multirow{2}{*}{ نوع ييوند } & \multirow{2}{*}{ كروه } \\
\hline ثراكي, (\%) & 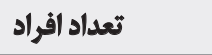 & & \\
\hline$\vartheta$ & if & اعتماد & \multirow{2}{*}{ ابوذر } \\
\hline זם & if & مشاركت & \\
\hline AV & 1. & اعتماد & \multirow{2}{*}{ ايثار } \\
\hline ve & 1. & مشاركت & \\
\hline$N$ & 1. & اعتماد & \multirow{2}{*}{ توسعه بايدار } \\
\hline Va & 1. & مشاركت & \\
\hline$\vartheta$ & $q$ & اعتماد & \multirow{2}{*}{ فجر } \\
\hline AT & $q$ & مشاركت & \\
\hline$n$ & if & اعتماد & \multirow{2}{*}{ ثامن الحجج } \\
\hline qv & if & مشاركت & \\
\hline 9. & 1. & اعتماد & \multirow{2}{*}{ فضاى سبز } \\
\hline จง & 1. & مشاركت & \\
\hline ז" & v & اعتماد & \multirow{2}{*}{ روستاى آباد } \\
\hline 9. & $v$ & مشاركت & \\
\hline
\end{tabular}




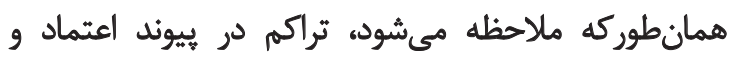

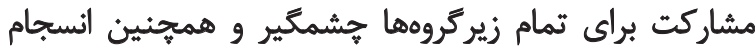

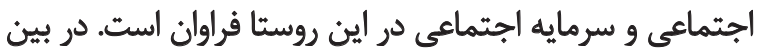

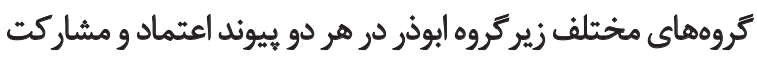

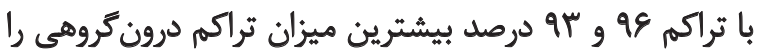

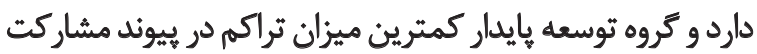

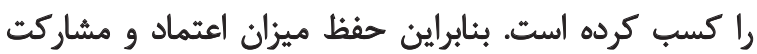

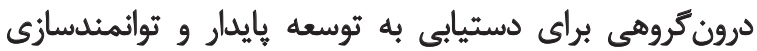

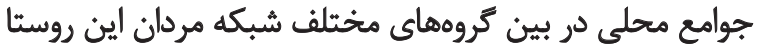

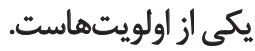

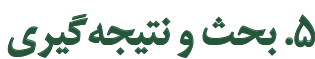

تحليل شبكه اجتماعى، رويكردى نوين در برنامهريزى براي

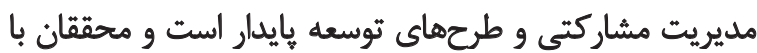

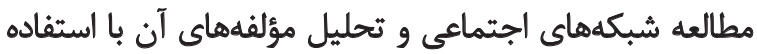

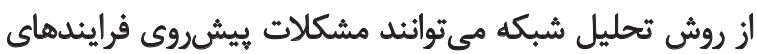

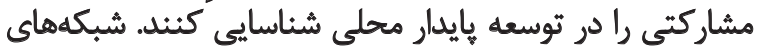

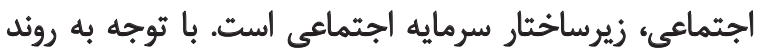

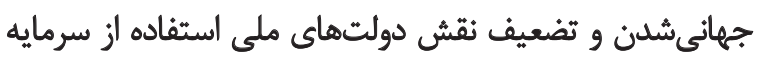

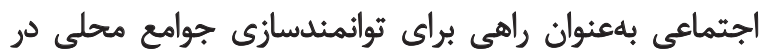

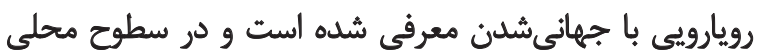

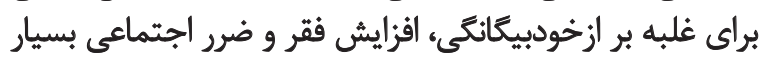

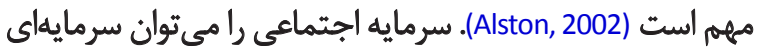

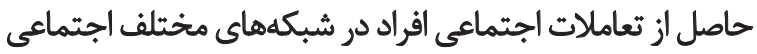

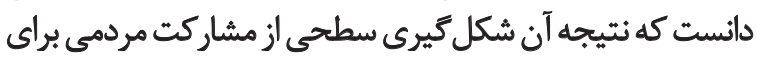

دستيابى به اهداف جمعى است (Kazemian \& Shafia, 2014).

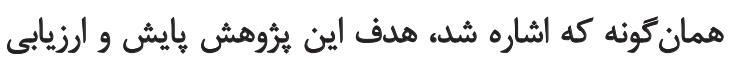

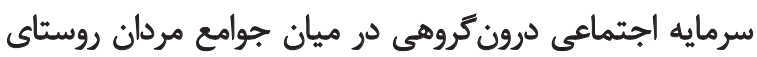

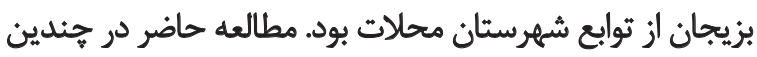

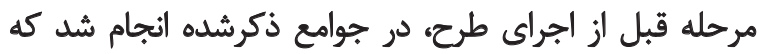

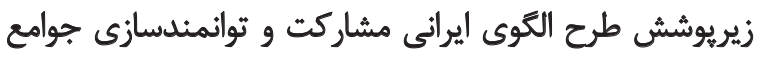

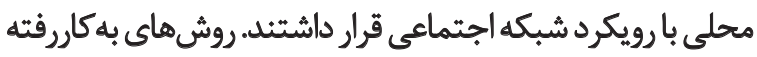

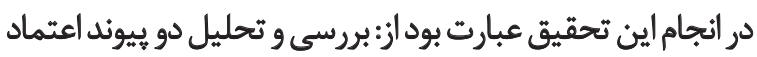

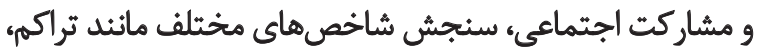

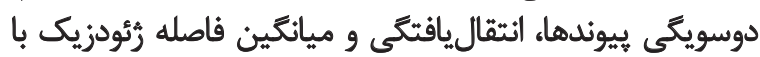
استفاده از روش تحليل شبكه اجتماعى.

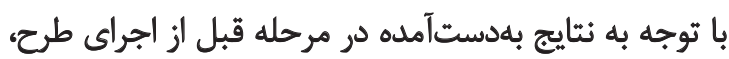

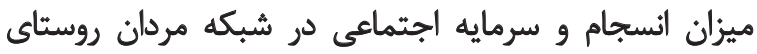

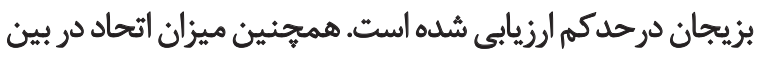

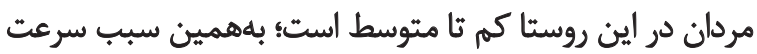

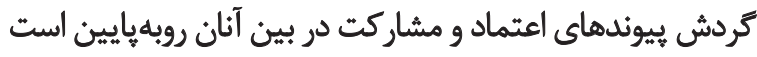

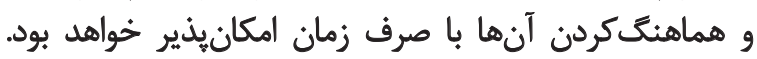

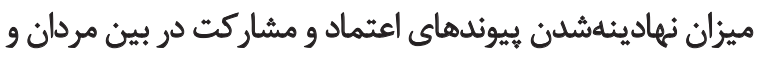

مىتوان كفت سرعت كردش اعتماد و مشاركت در اين مرحله

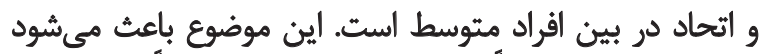

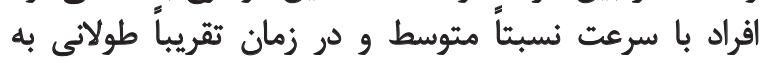

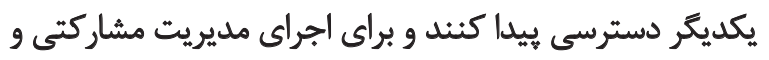

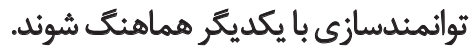

براساس ثنايج جدول ذكرشده در طول اجراى طرح درئ در روني

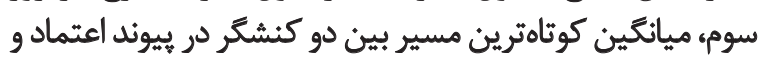

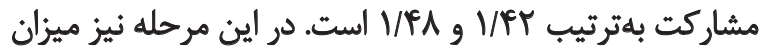

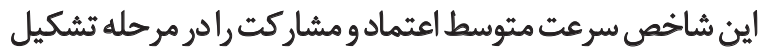

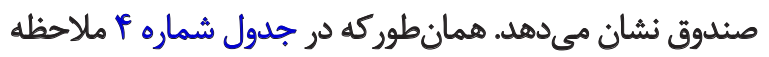

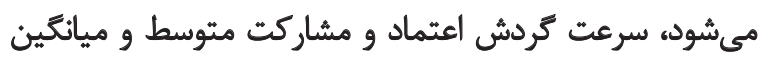

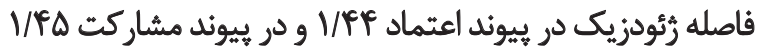

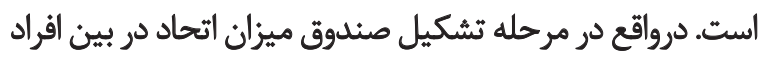

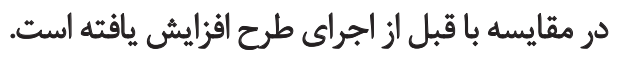

بلهوركلى نتايج مربوط به ميزان اين شاخص در دو دوانيوند

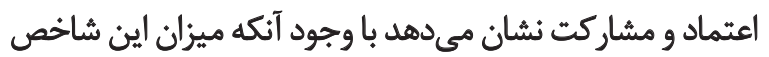

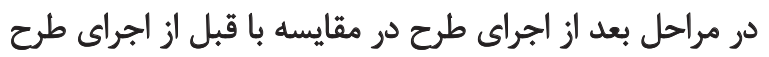

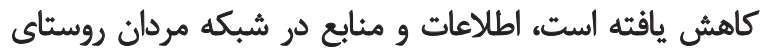

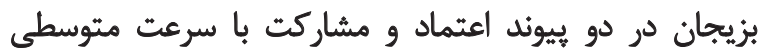

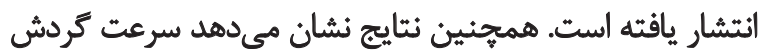

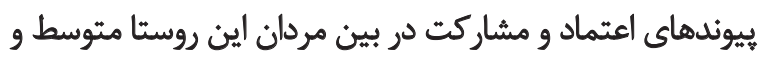

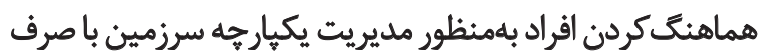

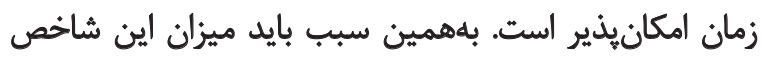

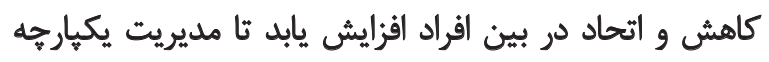

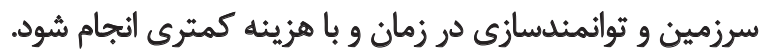

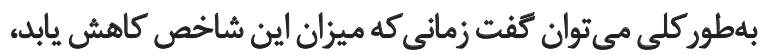

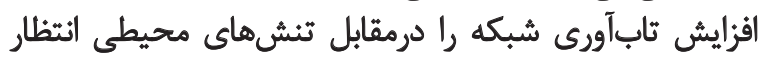

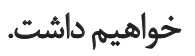

\section{ميزان شاخص تراكم در بين زيركروههاى شبكه مردان} روستاى بزيجان

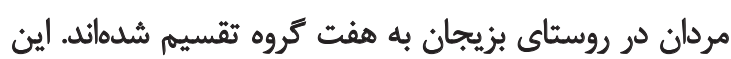

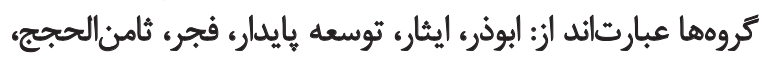

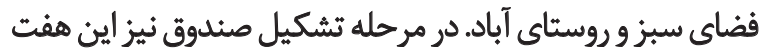

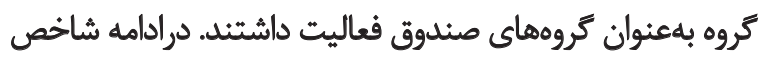

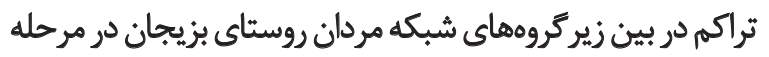

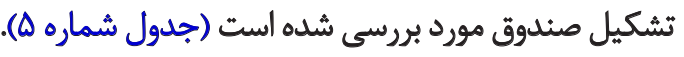

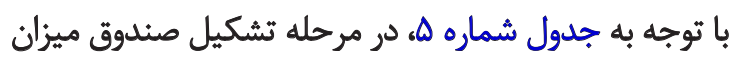

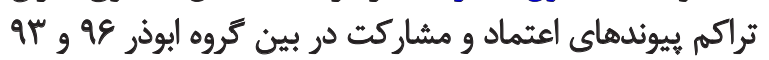

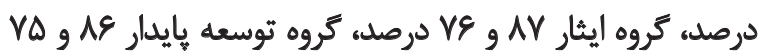

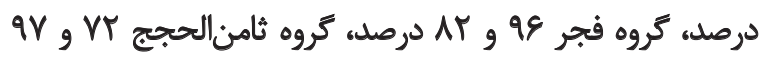

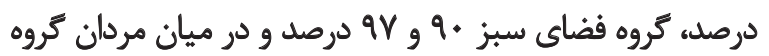
روستاى آباد اين ميزان • ج و و جو درصد است. 
جالشها و فرصتهاى ييشرو وجود دارد. ازجمله عوامل مؤثرد در توسعه بايدار روستايى ميى توان به سرمايه

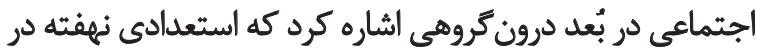

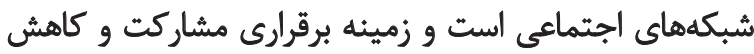

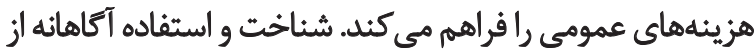

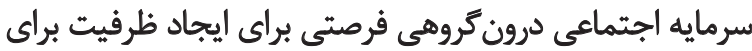
مشاركت در توسعه پايدار است (Shafia, 2010).

بلهور كلى دستيابي به موفقيت در توسعه بايدار روستايي، نيازمند

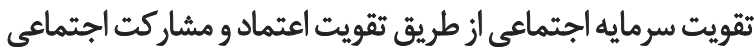

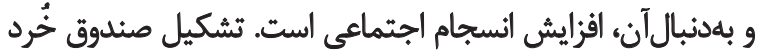

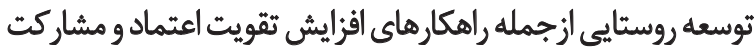

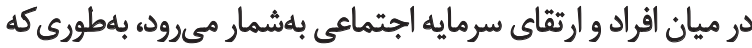

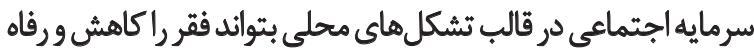

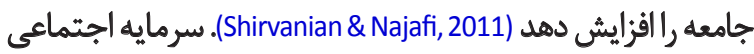

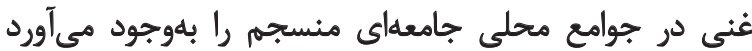

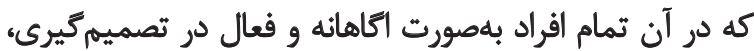

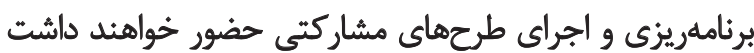

(Bhagavatula, Elfring, Van Tilburg, Van de Bunt, 2010)

بنابراين افراد بهصورت برابر قدرت دستيابى به فرصتهاي

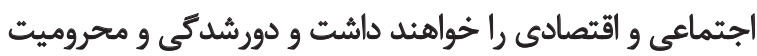

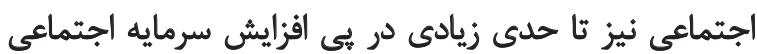

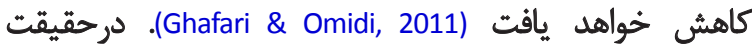

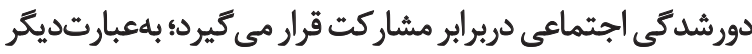

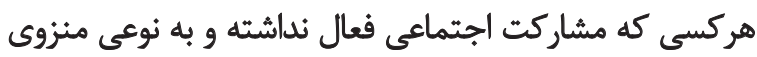

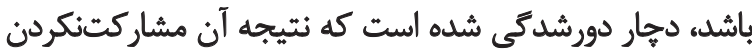

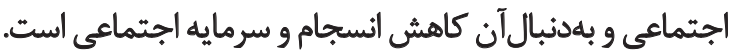

دريايان مىتوان كفت بهمنظور برنامهريزى و اجراي توسعه

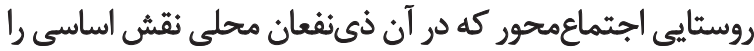

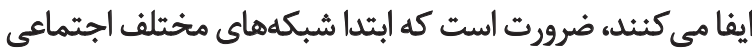

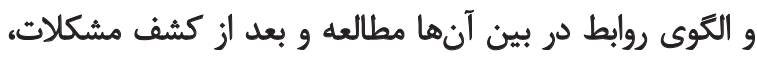
راهبردها و سياستهاى لازم تدوين شود (Ebrahimi et al., 2014).

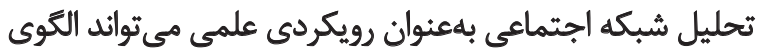

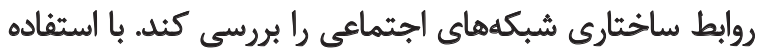

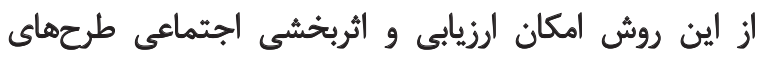

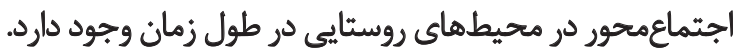

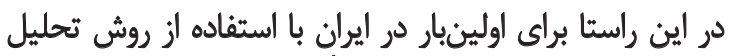

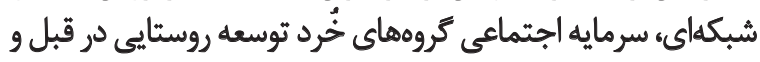

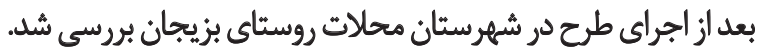

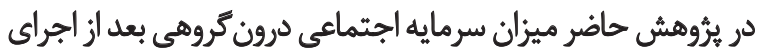

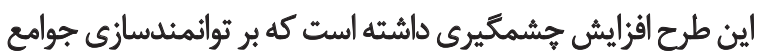

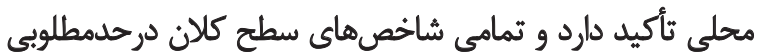
افزايش يافته است (Ghorbani, 2014).

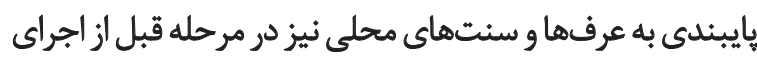

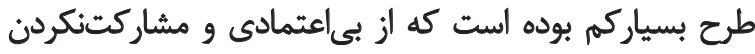
مثقابل در بين افراد حكايت دارد.

در مراحل بعدى طرح ميزان اعتماد و مشاركت بين مردان

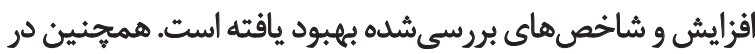

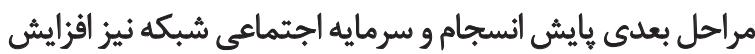

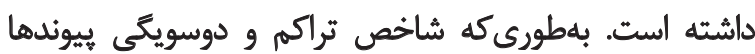

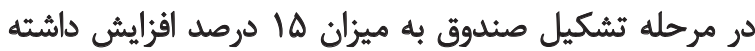

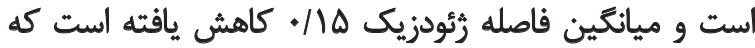

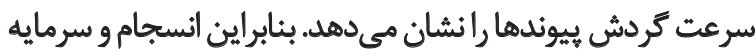

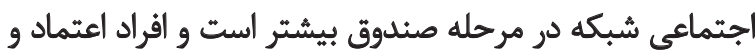

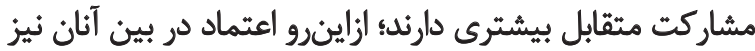

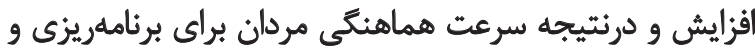

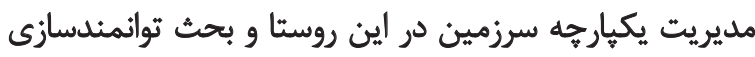

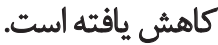

همان طوركه كفته شد ميزان سرمايه اجتماعى فراوان همكارى

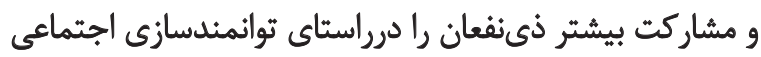

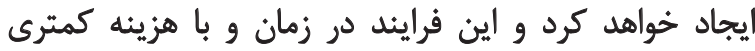

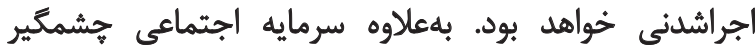

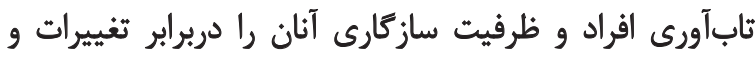

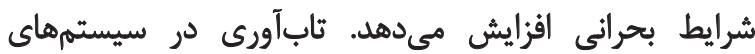

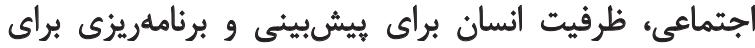

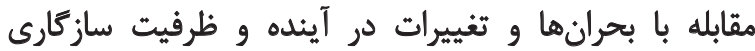

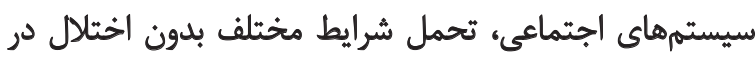

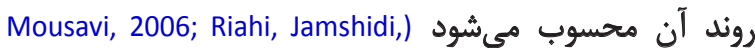
.(Jamini, \& Cheraghi, 2013

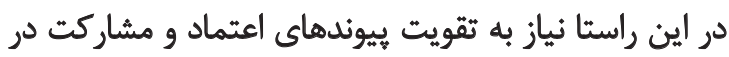

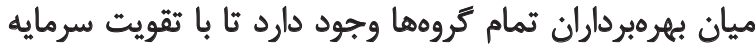

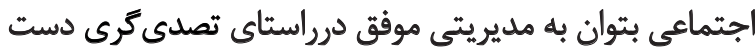

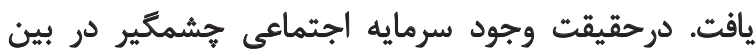

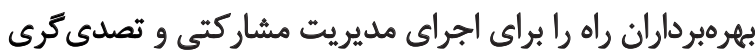

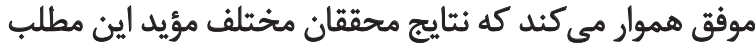

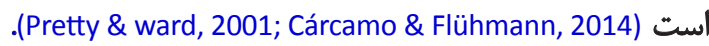

همجنين با توجه به اهميت زمان و سرعت هماهنغ مركردن

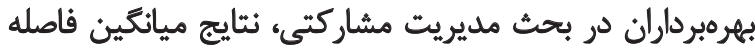

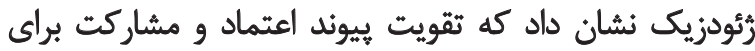

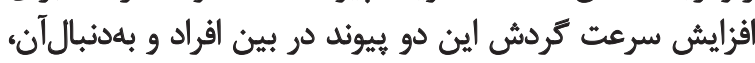

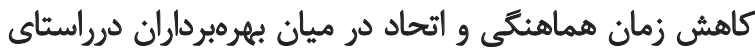

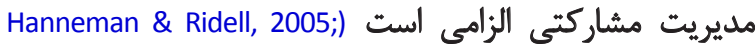
Rezaie, 2013; Ghorbani, 2015a, Ghorbani, 2015c براى اجراى طرحهاى مشاركتى درراستاى مديريت روستايى

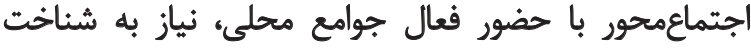




\section{References}

Alston, M., (2002). Social Capital in Rural Australia. Journal of Rural Socity, 12(2), 93-104. doi: 10.5172/rsj.12.2.93

Bastani, S., \& Raeesi, M., (2011). [Network analysis method: the use of the network approach in the open source community (Persian)]. Journal of Iranian Social Studies, 5(2), 33-59.

Bhagavatula, S., Elfring, T., Van Tilburg, A., \& Van De Bunt, G. G. (2010). How social and human capital influence opportunity recognition and resource mobilization in India's handloom industry. Journal of Business Venturing, 25(3), 245-260.

Bodin, Ö., Crona, B., \& Ernstson, H. (2006). Social networks in natural resource management: what is there to learn from a structural perspective [Internet]. Ecology and Society, 11(2). Retrieved from http://www.ecologyandsociety.org/vol11/iss2/resp2/

Bullen, P., \& Onyx, J. (1999). Social capital: Family support services and neighbourhood and community centres in NSW. Glebe: Australia Local Community Services Association.

Cárcamo, P. F., Garay-Flühmann, R., \& Gaymer, C. F. (2014). Collaboration and knowledge networks in coastal resources management: how critical stakeholders interact for multiple-use marine protected area implementation. Ocean \& Coastal Management, 91, 5-16. doi: 10.1016/j.ocecoaman.2014.01.007

Dughayi, M. (2013). [Motivational strategies of public collaboration in local sustainable development (Persian)]. Paper presented at the Congress of Architecture, Urban Planning and Sustainable Development, Mashhad, Iran, 26 December 2013.

Ebrahimi, F., Ghorbani, M., Salajegheh, A., \& Mohseni Saravi, M. (2014). [Social network analysis of local stakeholders in action plan for water resources co-management (Case study: Jajrood River in Latian watershed, Darbandsar village) (Persian)]. Iranian Journal of Watershed Management Science and Engineering, 8(25), 4756.

Farahani, H., Eynali, J., \& Abdoli, S. (2013). [Evaluate the role of social capital in the development of rural areas (Case Study: Mashhad district Mighan city of Arak) (Persian)]. Journal of Applied Researches in Geographical Sciences, 13(29), 27-50.

Fukuyama, F. (2001). Social capital, civil society and development. Third World Quarterly, 22(1), 7-20.

Ghafari, G. R., \& Tajaldin, M. B. (2005). [Identify the components of social exclusion (Persian)]. Social Welfare Quarterly, 5(17), 33-55.

Ghafari, Gh., \& Omidi, R. (2011). [Quality of life (Persian)]. Tehran: Shirazeh Publication.

Ghorbani, M. (2014). [The report of national project: social network analysis; modeling, policy-making and implementation of natural resources co-management (Vol. 1) (Persian)]. Tehran: Tehran University Press.

Ghorbani, M. (2015a). [Iranian pattern for collaboration and empowerment of local communities using social network (S.N.C.E.L.P) (Persian)]. Paper presented at the $3^{\text {rd }}$ International Conference on Natural-Caltural Heritage for Sustainable Development in Rural Areas, Rasht, Iran, 27-29 May 2014

Ghorbani, M. (2015b). [Monitoring and evaluation toolkit of social and policy networks in local community empowerment and integrated landscape management (Persian)] (Report paper). Tehran: University Tehran Press.

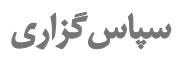

$$
\begin{aligned}
& \text { اين مقاله بركرفته از طرح كاربردى تحليل شبكه اجتماعى، }
\end{aligned}
$$

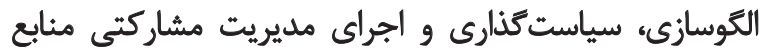

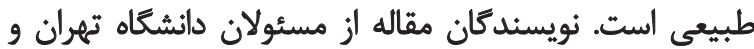

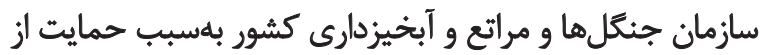

$$
\begin{aligned}
& \text { اين طرح قدردانى مى كنئد. }
\end{aligned}
$$


Ghorbani, M. (2015c). [Analysis and assessment of social-policy networks in grassroots association, institutions and sustainable development funds; Sarayan district, South Khorasan, RFLDL project (Persian)]. Tehran: Tehran University Press.

Ghorbani, M., Azarnivand, H., Mehrabi, A. A., Bastani, S., Jafari, M., Nayebi, H. (2013). [A new approach in policy-making and planning collaboration management of natural resources (Persian)]. Journal of Range and Watershed Management, 65(4), 553-68.

Hanneman, R. A., \& Riddle, M. (2005). Introduction to social network methods. California: University of California Riverside.

Jatel, N. (2013) Using social network analysis to make invisible human actor water governance networks visible-the case of the Okanagan vallay (PhD thesis). Columbia: British Columbia.

Kazemian, Gh., \& Shafia, S. (2014). [Evaluate the relationship between social capital development in the neighborhood of informal residents Bapayary new Shemiran (Persian)]. Journal of Social Sciences, 11(2), 1-24.

Luhmann, N. (1988). Familiarity, confidence, trust: problem and altervatives. In D. Gambetta (ed.), Trust: Making and Breaking Cooperative Relations (pp. 94-107). Oxford: Basil Blackwell.

Mousavi, M. N., Ghanbari, H. \& Esmaelzade, Kh. (2012). [Analyzing the relationship between social capital and sustainable development of urban areas of West Azarbaijan Province (Persian)]. Journal of Geography and Development, 10(27), 1-18.

Mousavi, M. T. (2006). [Social collaboration, one of the components of social capital (Persian)]. Social Welfare Quarterly, 6(23), 67-92.

Newig, J., Günther, D., \& Pahl-Wostl, C. (2010). Synapses in the network: learning in governance networks in the context of environmental management. Ecology and Society, 15(4), 24. Retrieved from http://www.ecologyandsociety.org/vol15/iss4/art24

Phi Khanh, H. L. (2011). The role of social capital to access rural credit: acase study at Dinh Cu and Van Quat Dong village in coastal of Thua Thien Hue province, Vietnam (MA thesis). Retrieved from Epsilon Sveriges Lantbruks Universitet Swedish University of Agricultural Sciences (Archive for Student Projects).

Plickert, G., Cote, R. R., \& Wellman, B. (2007). It's not who you know, it's how you know them: Who exchanges what with whom? Social Networks, 29(3), 405-29.

Pretty, J., \& Ward, H. (2001). Social capital and the environment. World Development, 29(2), 209-227.

Putnam, R. D. (2000). Bowling alone: the collapse and revival of American community. New York: Simon \& Schuster Publication.

Rahimi, Balkanloo, Kh. (2014). [Feasibility ssessment of the sustainability of land by using a combination of social network analysis and performance analysis of prospects. Case study: Semnan Province (Persian)] (MA thesis). Tehran: Tehran University.

Rahimi Balkanlou, Kh., M. Ghorbani, M. Jafari, \& Tavili, A. (2014). Analysis of the local stakeholders' network, social capital and cohesion in landscape co-management (case study: Changi rangeland Kalateh Roudbar-Damghan) (Persian)]. Journal of Watershed, 68(1), 47-64.

Rezaie, M. R. (2013). [Evaluating the economic and institutional resilience of urban communities to natural disasters using PROMETHE technique (Persian)]. Journal of Disaster Management, 2(3), 25-36.
Riahi, V., Jamshidi, A. R., Jamini, D., \& Cheraghi, R. (2013). [An evaluation of social capital and its influencing factors among villagers of Kermanshah province (case study: Uramanat Region) (Persian)]. Journal of Research and Rural Planning, 4, 1-6.

Salari Sardari, F. A., Beiranvandzadeh, M., \& Alizadeh, S. D. (2012) [Role of social capital in local sustainable development (Persian)] Hoviate Shahr, 19(8), 77-88.

Salari, F. (2014). [Modelling and network analysis of water Governance in Razin Watershed, Kermanshah (Persian)] (MA thesis). Tehran: Tehran University.

Salmani, M., Taghipour, F., Ramezanzade, M. \& Jalili, P. Z. (2008) [Investigation relationship between social capital and efficiency (Case study: Saffron producers of Ferdows county) (Persian)] Journal of Geography and Regional Development, 4(2), 23-45.

Scott, J. (2000). Social network analysis. London: Sage Publication.

Sepehri, M. M., \& Riahi, A., (2010). [Using social network analysis to extract knowledge management system in knowledge-based organizations (Persian)]. Journal of Science and Technology Diplomacy, 3(2), 81-94.

Shafia, S. (2010). [Relationship between informal settlements citizens with local sustainable development (Persian)] (MA thesis). Tehran: Allameh Tabataba'i University.

Shafiei, M., Abdolhoseini, M., Yari, A., Kargar, A., \& Pouyafar, A. M. (2013). [Natural resources participatory management and rural development planning in arid and semi-arid regions (Persian)]. Mashhad: Shoara Publication.

Shirvanian, A. B., \& Najafi, B. (2011). The role of social capital on welfare and rural Poverty Reduction : a case study of irrigation and drainage network of Doroudzan. Iranian Agricultural Economics Society, 5(3), 25-53.

Siwar, C., Alam, M. M., Murad, M. W., \& Al-Amin, A. Q. (2009). A review of the linkages between climate change, agricultural sustainability and poverty in Malaysia. International Review of Business Research Papers, 5(6), 309-21.

Stein, C., Ernstson, H., \& Barron, J. (2011). A social network approach to analyzing water governance: The case of the Mkindo catchment, Tanzania. Physics and Chemistry of the Earth, 36(14), 1085-092.

Stern, M. J., \& Coleman, K. J. (2015). The multidimensionality of trust: Applications in collaborative natural resource management. Society E Natural Resources, 28(2), 117-32.

Suzuki, E., Takao, S., Subramanian, S. V., Komatsu, H., Doi, H., \& Kawachi, I. (2010). Does low workplace social capital have detrimental effect on workers' health? Social Science $\mathcal{E}$ Medicine, 70(9), 1367-372.

Tanhaei, H., Hazrati, Z. (2014). Theoretical studies of social capital in Iran, Journal of Behavioral Sciences , 2(3), 29-52.

Taylor, J. (2002). Sustainable development: A dubious solution in search of a problem. Massachusetts, Washington, D.C.: Cato Institute. 
